\title{
New Routes to Functionalize Carbon Black for
}

\section{Polypropylene Nanocomposites}

Céline Shepherd, ${ }^{1}$ Emina Hadzifejzovic, ${ }^{1}$ Fatma Shkal, ${ }^{3}$ Kerstin Jurkschat, ${ }^{2}$ Jonathan Moghal, ${ }^{2}$ Emily M. Parker, ${ }^{1}$ Montree Sawangphruk, ${ }^{4}$

Daniel R. Slocombe, ${ }^{3}$ John S. Foord, ${ }^{1}$ Mark G. Moloney ${ }^{1}$

${ }^{1}$ Department of Chemistry, Chemistry Research Laboratory, University of Oxford, Mansfield Road, Oxford, OX1 3TA, UK

${ }^{2}$ Department of Materials, University of Oxford, Parks Road, OX1 3PH, Oxford, UK

${ }^{3}$ School of Engineering, Cardiff University, The Queen's Buildings, The Parade, Cardiff, CF24 3AA, UK

${ }^{4}$ Department of Chemical Engineering, Faculty of Engineering, Kasetsart University, 50 Paholyothin Road, Jatujak, Bangkok 10900, Thailand 


\section{ABSTRACT}

Methods for chemical surface functionalization for carbon black (CB) nanoparticles were studied to produce $(\mathrm{CB})$ /polypropylene (PP) nanocomposites with superior electrical and thermal properties. Nanoparticle dispersion is known to directly control the extent to which nanocomposites maximize the unique attributes of their nano-scale fillers. As a result, tailored nanoparticle surface chemistry is a widely utilized method to enhance the interfacial interactions between nanoparticles and polymer matrices, assisting improved filler dispersion. In this work, a rapid chemical functionalization approach using a number of diarylcarbene derivatives, followed by the azo-coupling of substituted diazonium salts, for the covalent introduction of selected functional groups to the CB surface, is reported. Characterization of the modified $\mathrm{CB}$ by XPS, TGA, CHN and ATR-IR collectively confirmed surface functionalization, estimating surface grafting densities in the order of $10^{13}$ and $10^{14}$ molecules $/ \mathrm{cm}^{2}$. Nanocomposites, synthesized by solvent mixing PP with pristine and modified $\mathrm{CB}$, demonstrated macroscopic property changes as a result of the nanoparticle surface functionalization. Pronounced improvements were observed for PP nanocomposites prepared with a dodecyl-terminated diaryl functionalized $\mathrm{CB}$, in which TEM analysis established improved nanofiller dispersion owing to the enhanced CB-PP interfacial interactions in the nanocomposite. Observed dielectric relaxation responses at $20 \mathrm{wt} \%$ loading and a reduced percolation threshold realized conductivities of $1.19 \times 10^{-4} \mathrm{Scm}^{-1}$ at 10 wt. \%, compared to $2.62 \times 10^{-15} \mathrm{Scm}^{-1}$ for pristine $\mathrm{CB} / \mathrm{PP}$ nanocomposites at the same filler loading. In addition, thermal properties signify an increase in the number of nucleation sites by the raised degree of crystallinity as well as increased melting and crystallization temperatures. 


\section{INTRODUCTION}

Nanocomposites exploit the unique properties of both nanomaterials and polymers, and are emerging as an important class of multifunctional materials with superior electrical ${ }^{1}$, thermal ${ }^{2}$, mechanical ${ }^{3}$, optical ${ }^{4}$ and antibacterial ${ }^{5}$ functionalities. Nanocomposites therefore exhibit substantial potential for applications in electrical, automotive and aerospace industries.

It is widely acknowledged that polymer nanocomposite properties are dependent upon a multitude of factors. First, the method used to prepare the nanocomposite will directly influence the interfacial interactions between the nanofiller and polymer matrix. Typically, nanocomposites are prepared by melt compounding, solvent blending or in situ polymerization methods. ${ }^{6,7}$ Second, the chemistry of the selected polymer, including its polarity, degree of crystallinity and viscosity, all contribute to the control of the overall nanocomposite properties. ${ }^{8}$ Equally, the surface area, specific surface chemistry, porosity, aspect ratio and morphology of the selected nanofiller will further dictate the performance of the polymer nanocomposites. ${ }^{9}$ In particular, a key property of $\mathrm{CB}$ in nanocomposite technology is the 'structure' of the $\mathrm{CB}$. This term describes the size and shape of the $\mathrm{CB}$ aggregates, which are defined units of fused primary CB nanoparticles. It is the presence of $\mathrm{CB}$ aggregates in polymer nanocomposites which enables electrical conductivity at lower loadings than are otherwise predicted for a system with separate primary spherical particles. ${ }^{10}$ However, attractive Van der Waals interactions between aggregates and poor compatibility of the filler with the polymer matrix promotes the formation of $\mathrm{CB}$ super-agglomerates. This is unfavorable for higher performance nanocomposites as high filler loadings are required to achieve electrical conductivity in the polymer nanocomposite, compromising the attractive innate mechanical and processability properties of the original polymer. ${ }^{11}$ 
Particle functionalization has therefore been employed as a versatile and useful strategy in nanocomposite technology, both for the improvement of the filler-matrix interfacial interactions as well as the inhibition of unfavorable aggregate agglomeration, thereby improving the dispersion of the nanofiller. ${ }^{12}$ In the study reported here-in, nanocomposites prepared using polypropylene (PP), selected as a widely used commodity thermoplastic, and carbon black (CB), a convenient, inexpensive conductive amorphous carbon nanofiller, were explored to determine if chemical surface functionalization can lead to enhanced electrical and thermal nanocomposite properties. CB was modified using diarylcarbene derivatives with different substitutions to tailor the surface chemistry of the nanofiller. Previously, diarylcarbene derivatives have provided a direct, versatile method for the irreversible introduction of desired functionality into materials. Examples include the surface modification of single walled carbon nanotubes (SWCNTs), ${ }^{13}$ fullerenes, ${ }^{14}$ hydrogenterminated diamond ${ }^{15}$ and silica ${ }^{16}$ as well as a comprehensive range of polymers. ${ }^{17,}{ }^{18}$ This approach permits changes to the surface chemistry, which allows for the introduction of colour, ${ }^{19}$ biocidal activity, ${ }^{20}$ biocompatibility ${ }^{21}$ as well as wettability. ${ }^{22}$ We have used two diarylcarbene functionalization approaches to modify CB nanoparticles: Route A used a twostep approach to introduce detectable nitrogen functionality as well as steric-stabilizing hexyl and dodecyl hydrocarbon chains to the surface. Route B used a one-step approach as a target synthesis for the direct introduction of a hydrocarbon-terminated diaryl unit onto the CB. Subsequently, Route B modified CB/PP nanocomposites were prepared to investigate the effect of the CB chemical functionalization upon the interfacial interactions in the polymer matrix, and any concomitant altered macroscopic properties. 


\section{EXPERIMENTAL SECTION}

Materials. Commercial Monarch ${ }^{\circledR} \mathrm{CB}$ (CB, M 430) was supplied from Cabot Corporation (Billerica, MA, USA). The CB possessed a primary particle size of $27 \pm 10 \mathrm{~nm}$ diameter, density $1.1-1.9 \mathrm{~g} / \mathrm{cm}^{3}$ (manufacturer's data), and a BET surface area $72.5 \mathrm{~m}^{2} / \mathrm{g}$. Commercial grade polypropylene (PP, 2440TC polypropylene copolymer with ethylene as co-monomer, MFI $55 \mathrm{~g} / 10 \mathrm{~min}$ ) was provided by IRPC Ltd., Thailand. All other reagents were used as supplied from Alfa Aesar Chemicals Ltd., Sigma-Aldrich Chemicals and Lancaster Chemicals Ltd.

Nanoparticle Functionalization. CB nanoparticles were functionalized in Route A using diaryldiazo derivatives followed by a diazonium coupling reaction (Scheme 1).

Scheme 1. Route A Synthesis and two-step CB surface modification.

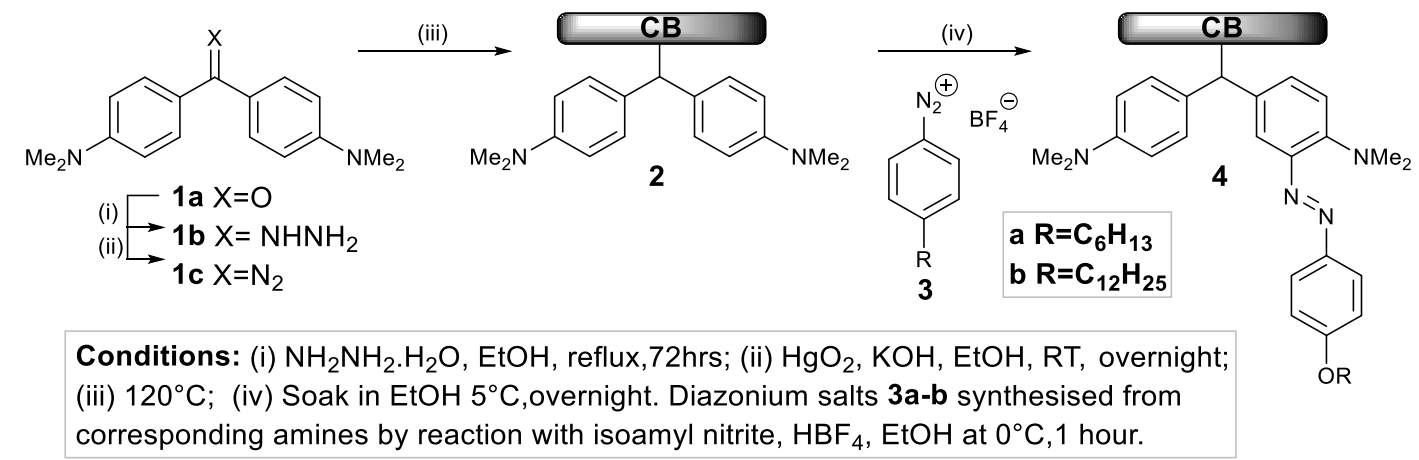

Route A used bis(4-(dimethylamino)phenyl)diazomethane, as a first step to functionalize the $\mathrm{CB}$ to produce modified CB_2. This diaryldiazo compound was prepared from the commercially available Michler's ketone in a two-step synthesis, via conversion to the hydrazine product, as previously reported ${ }^{18}$ For the modification step, diazo $1 \mathbf{c}$ was dissolved in $\mathrm{Et}_{2} \mathrm{O}$ and sonicated with addition of the $\mathrm{CB}$ nanoparticles, after which solvent evaporation in vacuo afforded the diazo compound physisorbed onto the $\mathrm{CB}$ surface. Thermal decomposition of the labile diazo precursor generated the transient carbene and dinitrogen, 
and the in situ generated carbene irreversibly modified the CB surface. When cool, the modified CB nanoparticles were washed thoroughly with acetone $(500 \mathrm{~mL})$ and dried for 1 hour in vacuo. The surface of modified CB_2 was further manipulated using diazonium coupling reactions by treatment with hydrocarbon-terminated diazonium salts $\mathbf{3 a - b}$ (Scheme 2).

Scheme 2. Route A synthesis of diazonium salts for diazonium coupling onto pre-functionalized CB_2.

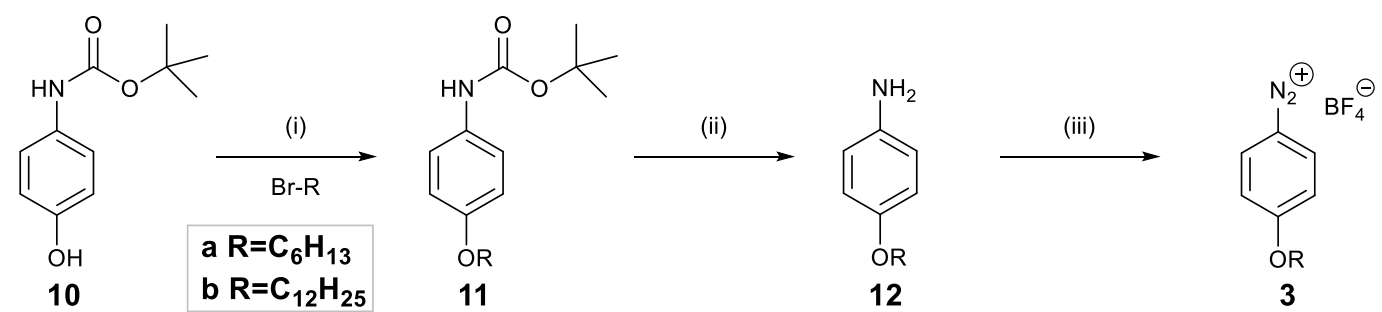

Conditions: (i) $\mathrm{MeCN}, \mathrm{K}_{2} \mathrm{CO}_{3}$, reflux; (ii)TFA:DCM 1:6; (iii) isoamyl nitrite, $\mathrm{HBF}_{4}, \mathrm{EtOH}$ at $0^{\circ} \mathrm{C}, 1 \mathrm{Hour}$.

The diazonium salts 3a-b were prepared by reaction of tert-butyl-(4-(hexyloxy)phenyl) carbamate 10 with the required alkyl bromides followed by BOC removal, to generate the aniline products, 12a-b. Reaction with isoamylnitrite in tetrafluoroboric acid produced the corresponding diazonium salts and their presence was confirmed using the $\mathrm{H}$-acid test. ${ }^{17}$ CB_2 was added to the in situ generated diazonium salts solutions and the mixture left overnight before washing with acetone and drying in vacuo, to generate two-step modified CB_4a and CB_4b, possessing terminal hexyl and dodecyl groups respectively.

Route B (Scheme 3) permitted the introduction of the steric stabilizing alkyl chains in a fourstep synthesis, using a more direct route by a single diazo modification to functionalize the CB nanoparticles. 
Scheme 3. Route B synthesis and one-step CB surface modification.

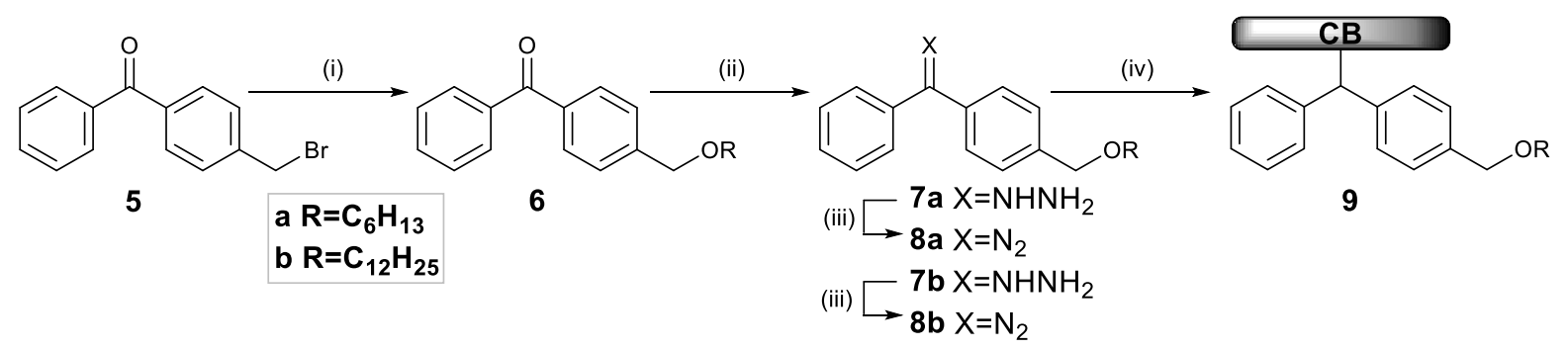

Conditions: (i) $\mathrm{NaH}, \mathrm{ROH}, \mathrm{THF}, \mathrm{Stir}, 18 \mathrm{hrs}$; (ii) $\mathrm{NH}_{2} \mathrm{NH}_{2} \cdot \mathrm{H}_{2} \mathrm{O}$, EtOH, reflux, 18hrs;

(iii) $\mathrm{MnO}_{2}, \mathrm{KOH}, \mathrm{MeOH}, \mathrm{RT}$, overnight; (iv) $120^{\circ} \mathrm{C}$.

Williamson ether reaction with 4-bromomethylbenzophenone and hexanol or dodecanol generated hydrocarbon-terminated diaryl ketocompounds $\mathbf{6 a - b}$ and following treatment with hydrazine monohydrate, afforded the subsequent hydrazone derivatives $\mathbf{7 a - b}$. Oxidation with manganese dioxide produced the target diazo compounds, which were reacted with $\mathrm{CB}$ to give functionalized CB_9a and CB_9b, that is, with hexyl and dodecyl terminating groups respectively. Detailed preparation and characterisation data of the synthesis of the diazo compounds and diazonium salts is included in the Supporting Information.

Nanoparticle Characterisation. Thermogravemetric analysis (TGA) and differential scanning calorimetry (DSC) was conducted using a Perkin Elmer Simultaneous Thermal Analyzer, STA6000. Experiments were performed under nitrogen and samples $(\sim 12 \mathrm{mg})$ were loaded in an alumina pre-conditioned pan. For carbene insertion analysis, the sample was heated at a ramp rate of $10{ }^{\circ} \mathrm{C} \mathrm{min}^{-1}$ and a sigmoidal baseline was used to evaluate the reaction enthalpy. For nanoparticle analysis, samples were heated from $30{ }^{\circ} \mathrm{C}$ to $850{ }^{\circ} \mathrm{C}$ at a ramp rate of $20^{\circ} \mathrm{C} \mathrm{min}^{-1}$.

Combustion analysis (CHN) of $5 \mathrm{mg}$ samples was conducted by MEDAC Ltd.

X-ray photoelectron spectroscopy (XPS) samples were prepared in a pellet press, and affixed to the sample stub using double-sided carbon tape. Analysis was performed using a VG - Escalab X-Ray Photoelectron Spectrometer VGX900 using Al Ko radiation with an 
energy of $1486.6 \mathrm{eV}$ at an operating pressure $<1 \times 10^{-8} \mathrm{mBar}$. The Pass Energy was set at 50 $\mathrm{eV}$ for the wide scan of the sample, and $20 \mathrm{eV}$ for scans of specific areas; $\mathrm{C} 1 \mathrm{~s}, \mathrm{~N} 1 \mathrm{~s}, \mathrm{O} 1 \mathrm{~s}$. Casa XPS peak fitting software was used to analyse spectra and a reference charge correction of $284.5 \mathrm{eV}$ for $\mathrm{C} 1 \mathrm{~s}$ used. ${ }^{23}$ The area under the elemental peaks and standard sensitivity factors $(\mathrm{C}, 1 ; \mathrm{O}, 2.93 ; \mathrm{N}, 1.8)^{24}$ were used to calculate relative percentage elemental abundance within the surface and near-surface sampling depth of the XPS.

Attenuated total reflectance - infra red spectroscopy (ATR-IR) was conducted using a BioRad FTS-6000 Fourier Transform Infrared Spectrometer fitted with DuraSamplIR Diamond ATR accessory. Nanoparticle samples were screwed into position using the compression tip on the diamond accessory and the spectra collected with a resolution of $0.25 \mathrm{~cm}^{-1}$ from 6000 $700 \mathrm{~cm}^{-1}$ as the sum of 256 scans.

BET Brunauer - Emmett - Teller (BET) surface area analysis was performed at $-195.9^{\circ} \mathrm{C}$ by nitrogen sorption experiments using a Micromeritics Tristar II PLUS surface area and pore size analyzer. Before analysis, samples $(\sim 0.8 \mathrm{~g})$ were heated at $200{ }^{\circ} \mathrm{C}$ overnight using a Micromeritics VacPrep 061 sample degas system.

Nanocomposite Preparation and Processing. Nanocomposite samples were prepared by solvent mixing methods, adapted from general procedures in the literature. ${ }^{25-27} \mathrm{PP}$ pellets $(0.15 \mathrm{~g})$ were dissolved in toluene $(10 \mathrm{~mL})$ under reflux $\left(130{ }^{\circ} \mathrm{C}\right)$ for 30 minutes. Subsequently, pristine and modified CB at 10, 15, 20, 25 and 30 wt. \% of PP were added in a hot suspension in toluene $(2 \mathrm{~mL})$ to the dissolved PP in toluene. Following 10 minutes stirring, the PP/CB suspension was sonicated for 30 minutes in an ultrasonic bath and dried in vacuo. For TEM and dielectric analysis, nanocomposite samples were pressed into films (15 $\mu \mathrm{m}$ and $50 \mu \mathrm{m}$, respectively) using a Specac Film Maker. The selected steel spacer was fitted between two optically polished platens, which held the nanocomposite sample between 
aluminum foil sheets. Heat and pressure treatment at $170{ }^{\circ} \mathrm{C}$ and 0.5 Torr was followed by cooling before removal for analysis.

Samples for conductivity measurements were prepared by compression molding into plaques $\left(1 \times 1 \times 0.1 \mathrm{~cm}^{3}\right)$ using a hot press $\left(200-190{ }^{\circ} \mathrm{C}\right)$ for 30 minutes, at a final pressure of $0.5 \mathrm{~T}$.

Nanocomposite Characterisation Nanocomposite plaques were silver pasted ${ }^{28}$ on each pair of parallel sides, and the sheet resistance measured by the two-point probe method using a Keithley Electrometer 617. For highly resistive samples $\left(\mathrm{R}>10^{9}\right)$, the bias voltage $(20 \mathrm{~V})$ was applied and the resistance calculated from the voltage-current ratio. Dielectric analysis was performed using a PNA-L Vector Network Analyzer N5232 and a flat coaxial reflectance probe with a $1.6 \mathrm{~mm}$ aperture. Prepared nanocomposite films $(50 \mu \mathrm{m})$ were held in place using a PTFE stub to ensure good contact between the probe and samples. The diameter of the center conductor of the coaxial probe was $0.3 \mathrm{~mm}$ and the diameter of the outer conductor was $1.6 \mathrm{~mm}$. The samples were each measured more than 50 times, at different positions of the film, in the frequency range $10 \mathrm{MHz}-10 \mathrm{GHz}$ at room temperature.

TEM Samples were prepared from nanocomposite films $(15 \mu \mathrm{m})$ and imbedded in epoxy for imaging, low to high magnification. Experiments were conducted on a JEOL 2010 analytical TEM, with a LaB6 electron gun operable between 80 and $200 \mathrm{kV}$. The TEM has a resolution of $0.19 \mathrm{~nm}$, an electron probe size down to $0.5 \mathrm{~nm}$ and a maximum specimen tilt of \pm 10 degrees along both axes. It is equipped with an Oxford Instruments LZ5 windowless energy dispersive X-ray spectrometer (EDS) controlled by INCA.

Differential scanning calorimetry (DSC) was conducted using Perkin Elmer Simultaneous Thermal Analyzer, STA6000. For nanocomposite analysis, the samples under nitrogen were subjected to a heating run $\left(30-250^{\circ} \mathrm{C}\right)$, to remove the thermal history, followed by a cooling 
cycle $\left(250-30^{\circ} \mathrm{C}\right)$ and then heated beyond the decomposition of PP $\left(30-850{ }^{\circ} \mathrm{C}\right)$, at a ramp rate of $20^{\circ} \mathrm{C} \mathrm{min}^{-1}$. 


\section{RESULTS AND DISCUSSION}

\section{Modified CB Characterisation}

Surface analysis was performed to evaluate the success of the chemical functionalization routes used to modify the CB nanoparticles. Samples prepared by Route A include CB_2, directly modified by carbene insertion, and $\mathrm{CB}_{-} 4 \mathrm{a}$ and $\mathrm{CB} \_4 \mathrm{~b}$, modified by the two-step process of carbene insertion followed by azo-coupling of diazonium salts terminated with hexyl and dodecyl groups, respectively. Route B prepared samples include CB_9a and CB_9b, modified by one-step carbene insertion reactions of diaryldiazo complexes terminated in hexyl and dodecyl groups, respectively.

X-ray photoelectron spectroscopy (XPS) of pristine and modified CB. The main features on the wide spectrum of pristine $\mathrm{CB}$ include a dominant $\mathrm{C} 1 \mathrm{~s}$ photoemission peak at $\sim 285 \mathrm{eV}$ binding energy and a small $\mathrm{O} 1 \mathrm{~s}$ peak at $\sim 532 \mathrm{eV}$ binding energy. The relative elemental abundances which were found are included in Table 1.

Table 1. Chemical percentage composition by XPS and CHN.

\begin{tabular}{cccccccc}
\hline \multirow{2}{*}{ Sample } & \multicolumn{3}{c}{ XPS (\%) } & & \multicolumn{3}{c}{ CHN (\%) } \\
\cline { 2 - 4 } \cline { 7 - 8 } & $\mathbf{C}$ & N & $\mathbf{O}$ & & C & N & H \\
\hline Pristine CB & 98.4 & n.d & 1.6 & & 96.5 & $<0.1^{\mathrm{b}}$ & 1.2 \\
CB_2 & 96.5 & 1.4 & 2.1 & & 95.3 & 0.8 & 1.2 \\
CB_4a & 92.7 & 0.4 & 6.9 & & 95.2 & 0.4 & 0.9 \\
CB_4b & 91.8 & 1.1 & 7.1 & & 91.8 & 0.9 & 1.6 \\
CB_9a & 94.4 & n.d. & 5.6 & & 96.7 & $<0.1$ & 1.4 \\
CB_9b & 97.0 & n.d. & 3.0 & & 96.2 & 0.3 & 1.6 \\
\hline
\end{tabular}

${ }^{a}$ n.d not detected, the $\mathrm{N} 1 \mathrm{~s}$ peak could not be observed by XPS

${ }^{\mathrm{b}}$ The measurable detection limit of $\mathrm{CHN}$ is $<0.1 \% \mathrm{~N}$.

Oxygenated functionalities are a characteristic surface component of many types of CB and carboxylic, lactonic and phenolic groups are reported to be present on the $\mathrm{CB}$ used in this work. ${ }^{29}$ On this basis, reaction at the surface with diarylcarbene might be expected to lead to the formation of benzhydryl esters and ethers along with $\mathrm{C}-\mathrm{C}$ and $\mathrm{C}-\mathrm{H}$ insertion products. 
Overall, minor changes were observed between the $\mathrm{C} 1 \mathrm{~s}$ and $\mathrm{O} 1 \mathrm{~s}$ regions present on the pristine CB and modified CBs, as detailed in the Supporting Information. The XPS clearly identified the presence of nitrogen species, which were introduced to the CB surface following the Route A functionalization procedure. In contrast, $\mathrm{N}$ 1s features were not detected on pristine $\mathrm{CB}$ or Route $\mathrm{B}$ functionalized $\mathrm{CB}$, as would be expected.

In detail, one-step Route A functionalized nanoparticle CB_2 displays a notable feature in the $\mathrm{N}$ 1s region at $399.9 \mathrm{eV}$ binding energy (Figure 1), owing to the $\mathrm{NMe}_{2}$ group, present on the precursor diazo 1c, and now present on the CB surface.
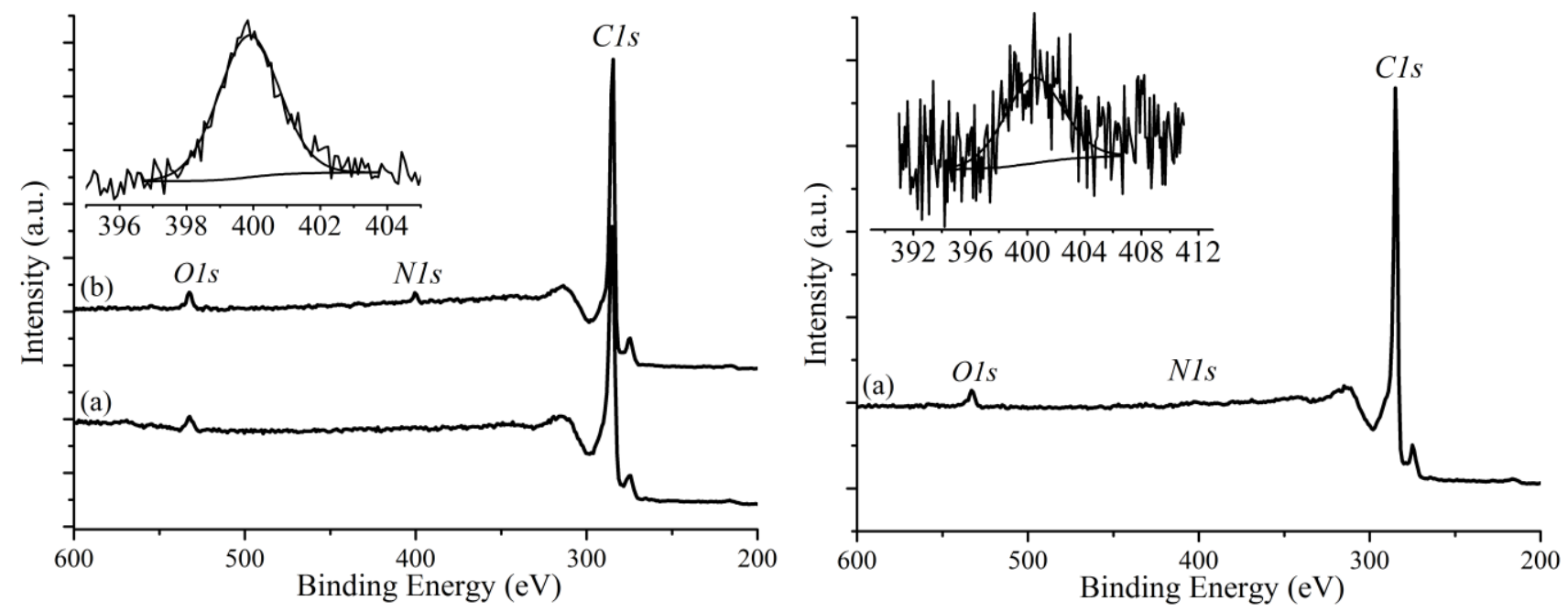

Figure 1. XPS survey scan of (a) pristine CB and Figure 2. XPS survey scan of (a) modified CB_2 (b) modified CB_2 (insert shows the high following treatment by thermal analysis (insert resolution scan of the $\mathrm{N} 1 \mathrm{~s}$ region.) shows the high resolution scan of the $\mathrm{N} 1$ s region.)

Two-step Route A modified CB_4a and CB_4b each display a N 1s peak at $400.3 \mathrm{eV}$ and $400.6 \mathrm{eV}$ binding energies, respectively, which can be attributed to the $\mathrm{NMe}_{2}$ and additional $\mathrm{N}=\mathrm{N}$ functionality present on the modified surface, consistent with detected azo-linkages reported elsewhere. ${ }^{16}$ It is likely that there is some variation of functionality that can be introduced as a monolayer coverage to the surface during the two-step functionalization procedure for CB_4a-b, and some possibilities are shown in Scheme 4. 
Scheme 4. Potential functionalized surface CB_4a-b following the two-step carbene insertion and diazonium coupling reactions: a) unsuccessful diazonium coupling reaction (same surface as $\mathrm{CB} \_2$ ) b) single azo-coupling to a single aromatic ring on $\mathrm{CB}$-2 c) dual azocoupling to both aromatic rings on $\mathrm{CB}$ 2 2 d) azo-coupling directly to the $\mathrm{CB}$ surface e) $\mathrm{C}-\mathrm{C}$ linkage to CB surface.

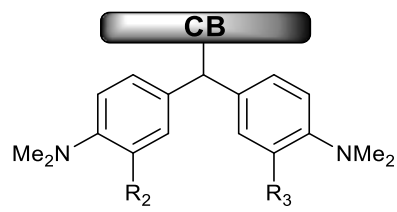

a) $R_{1}=R_{2}=H$

b) $R_{1}=H, R_{2}=$
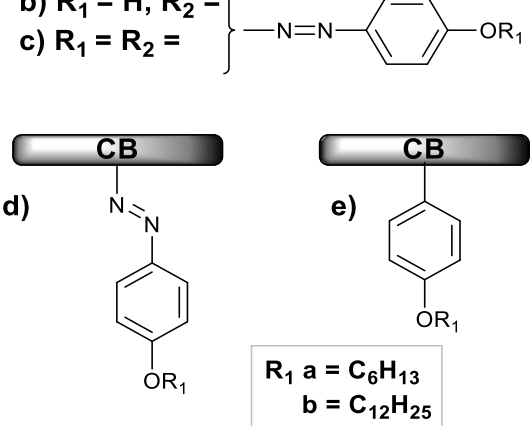

Some areas of the CB surface may remain unchanged following exposure to the diazonium salt solution, retaining the surface of $\mathrm{CB}_{-} 2$ (Scheme $4 \mathrm{a}$ ), or the unmodified $\mathrm{CB}$ surface. Otherwise, the diazonium coupling step is expected to occur at one or both of the rings on CB_2, due to the electron donating effect from each of the $\mathrm{NMe}_{2}$ groups present, to give single or dual insertion products (Scheme $4 \mathrm{~b}-\mathrm{c}$ ). Additionally, direct azo-coupling to $\mathrm{CB}$ (Scheme 4d), by reaction directed from phenolic groups present on the graphitic surface, has been reported, ${ }^{23}$ as well as C-C linkage (Scheme $4 \mathrm{e}$ ) initiated by the reduction of diazonium cations by the graphitic surface. ${ }^{30,31}$ However, for both instances, as the reaction with the diazonium salt is the second step onto pre-functionalized $\mathrm{CB}_{-} 2$, it is expected any direct linkages to the $\mathrm{CB}$ surface to be minimal. 
TGA-DSC thermal analysis of pristine and modified CB. The carbene insertion reaction to generate CB_9a was followed by thermal analysis (STA) (Figure 3), using a sample of CB coated with diazo $\mathbf{8 a}$.

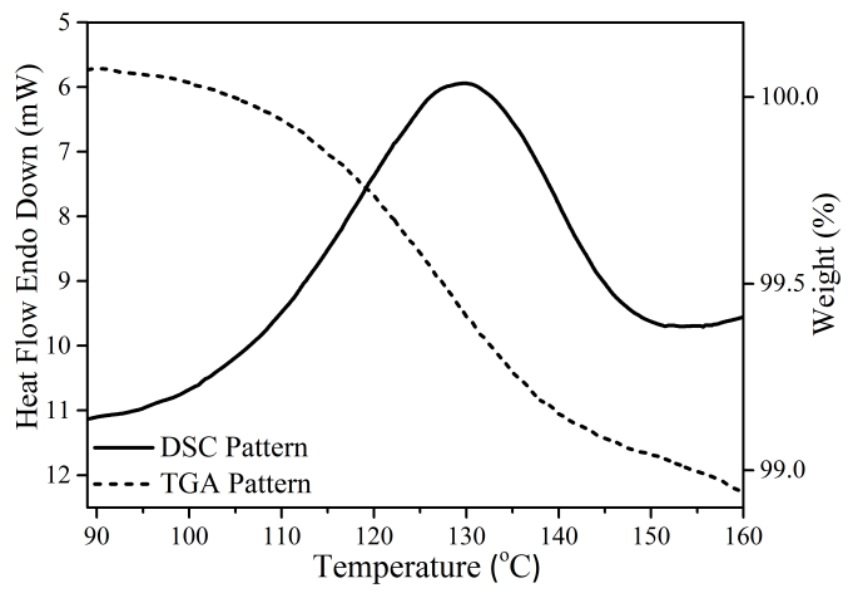

Figure 3. STA analysis of CB_9a surface modification reaction under nitrogen flow.

The diazo decomposition reaction was readily observed by the exothermic peak on the DSC thermogram, which shows a reaction enthalpy of $-45.6 \mathrm{~J} / \mathrm{g}$ with an extrapolated peak onset at $107.9{ }^{\circ} \mathrm{C}$ and peak decomposition temperature at $129.2{ }^{\circ} \mathrm{C}$. Additionally, the TGA thermogram indicated initial weight loss of the sample begins at $\sim 90{ }^{\circ} \mathrm{C}$ and plateaux at $\sim 160$ ${ }^{\circ} \mathrm{C}$, with a total weight loss of $0.165 \mathrm{mg}(1.13 \%)$, which can be attributed to the loss of $\mathrm{N}_{2}$ upon generation of the reactive carbene species, corresponding to a maximum conversion of the diazo compound to diarylcarbene of $33 \% .^{32,33}$

Further analysis of the functionalized CB by thermogravimetric analysis (TGA) (Figure 4) indicates the thermal stability of the modification and affords the opportunity to directly estimate the surface loading from the determined mass losses (Table 2). 


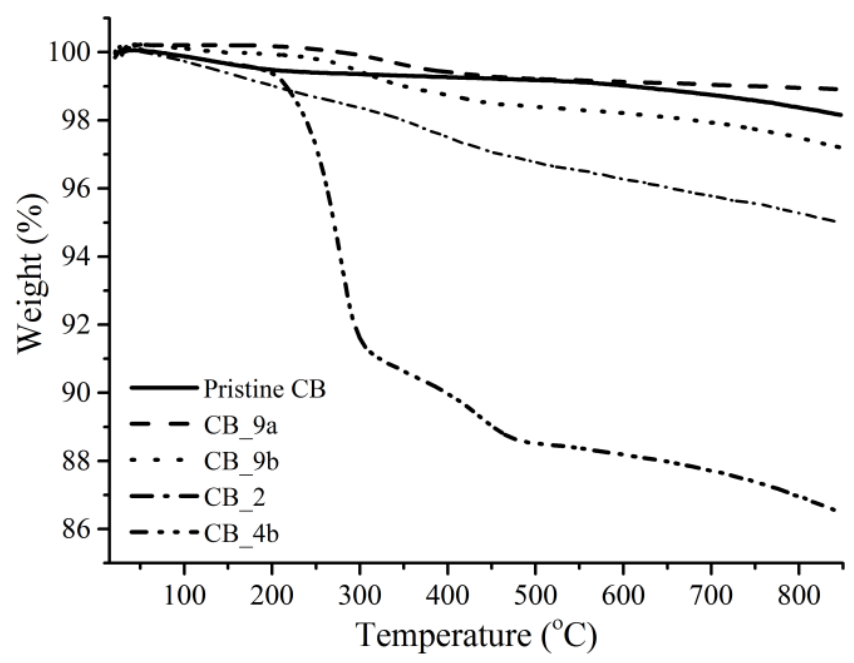

Figure 4. Thermogravimetric analysis of pristine and covalent modified CB under nitrogen flow.

The pristine and modified CB samples showed a similar weight loss, $0.3-1.0 \%$, in the temperature range $30-200{ }^{\circ} \mathrm{C}$, due to degassing and volatilization of water or residual solvents. ${ }^{34}$ Alternatively, in the $200-500{ }^{\circ} \mathrm{C}$ temperature range, Figure 4 shows the significant weight loss for the functionalized $\mathrm{CB}$ samples compared to pristine $\mathrm{CB}$ and this is attributed to the thermal decomposition, or cleavage, of the covalent modifications. One-step weight loss with onset decomposition temperatures in the range $255-326{ }^{\circ} \mathrm{C}$ is observed for the majority of the modified CB samples and is in agreement with reported thermal stability of similar covalent bound moieties on carbon-based substrates. ${ }^{13,35}$ In addition, CB_4b presents a two-step weight loss, with onset temperatures of $237.1{ }^{\circ} \mathrm{C}$ and $403.5{ }^{\circ} \mathrm{C}$, respectively. This result strongly indicates the success of the two-step reaction following the procedure with diazonium salts, either by azo-coupling to the CB_2 modification or directly to the $\mathrm{CB}$ surface. Subsequently, above $500{ }^{\circ} \mathrm{C}$ to the end of the TGA run, $\sim 850{ }^{\circ} \mathrm{C}$, a small similar weight loss can be observed for all the CB samples and generally this can be ascribed to the loss of appreciable non-graphitic fractions present on the $\mathrm{CB} .^{36}$ To confirm total removal of the modifications following thermal treatment, XPS analysis was performed to 
CB_2 retrieved after TGA analysis. Figure 2 indicates the loss of the nitrogen species by the survey scan, although it is not fully lost, indicated by the small $\mathrm{N} 1 \mathrm{~s}$ peak, $0.9 \%$ relative elemental abundance (Figure 2, insert). It is therefore evident that some of the surface modification survives the thermal treatment. Nonetheless, the percentage weight loss of modified $\mathrm{CB}$ can be compared to pristine $\mathrm{CB}$ during the thermal program $\left(30-800{ }^{\circ} \mathrm{C}\right)$, and taking into account the known surface modifier present and the experimental BET surface area of CB $\left(72.5 \mathrm{~m}^{2} / \mathrm{g}\right)$, an estimate of number of molecules present on CB can be calculated (Table 2).

Table 2. TGA and CHN analysis and loading calculations of pristine and modified CB.

\begin{tabular}{|c|c|c|c|c|c|c|c|}
\hline \multirow{3}{*}{ Sample } & \multicolumn{5}{|c|}{ TGA } & \multirow{2}{*}{\multicolumn{2}{|c|}{$\begin{array}{c}\text { CHN }^{\mathbf{b}} \\
\text { Surface Loading }^{\mathrm{a}} \\
\end{array}$}} \\
\hline & \multicolumn{3}{|c|}{ TGA weight loss (\%) } & \multicolumn{2}{|c|}{ Surface Loading ${ }^{a}$} & & \\
\hline & $\begin{array}{c}\text { 30-200 } \\
\left({ }^{\circ} \mathrm{C}\right)\end{array}$ & $\begin{array}{c}200-500 \\
\left({ }^{\circ} \mathrm{C}\right)\end{array}$ & $\begin{array}{c}500-800 \\
\left({ }^{\circ} \mathrm{C}\right)\end{array}$ & Moles/g & $\begin{array}{l}\text { Molecules } \\
/ \mathrm{cm}^{2}\end{array}$ & Moles/g & $\begin{array}{l}\text { Molecules } \\
/ \mathrm{cm}^{2}\end{array}$ \\
\hline Pristine CB & 0.5 & 0.3 & 0.8 & n.c. ${ }^{\mathrm{e}}$ & n.c. & n.c. & n.c. \\
\hline CB_2 & 1.0 & 2.3 & 1.4 & $1.2 \times 10^{-4}$ & $1.0 \times 10^{14}$ & $2.3 \times 10^{-4}$ & $1.9 \times 10^{14}$ \\
\hline $\mathrm{CB}-\overline{4} \mathrm{a}^{\mathrm{d}}$ & n.m. ${ }^{\mathrm{c}}$ & n.m. & n.m. & n.c. & n.c. & $4.8 \times 10^{-5}$ & $4.0 \times 10^{13}$ \\
\hline $\mathrm{CB}-4 b^{\mathrm{d}}$ & 0.7 & 10.9 & 1.6 & $1.6 \times 10^{-5}$ & $1.3 \times 10^{14}$ & $1.1 \times 10^{-4}$ & $9.0 \times 10^{13}$ \\
\hline $\mathrm{CB}^{-}-9 \mathrm{a}$ & 0.7 & 1.9 & 1.4 & $8.5 \times 10^{-5}$ & $7.1 \times 10^{13}$ & n.c. & n.c. \\
\hline $\mathrm{CB}-9 \mathrm{~b}$ & 0.3 & 1.5 & 0.9 & $2.9 \times 10^{-4}$ & $2.4 \times 10^{13}$ & n.c. & n.c. \\
\hline \multicolumn{8}{|c|}{$\begin{array}{l}{ }^{\mathrm{b}} \mathrm{CHN} \text { surface loadings calculated from detected nitrogen content present on modified CB. } \\
{ }^{c} \text { n.m. not measured - TGA was not performed for sample CB_4a. }\end{array}$} \\
\hline
\end{tabular}

TGA analysis therefore estimates the surface loading to be in the range of $2.4 \times 10^{13}$ to 1.3 $\times 10^{14}$ molecules $/ \mathrm{cm}^{2}$, a comparable result to previous work using diaryldiazo modifications. ${ }^{16}$ It can be noted that Route A modified CB_4b displays the highest loading of $1.3 \times 10^{14}$ molecules $/ \mathrm{cm}^{2}$, indicating the superior efficiency of the two-step carbene and diazonium modification procedure. Further, the TGA data from $\mathrm{CB}_{-} 4 \mathrm{~b}$ can be used to assess if single or dual azo-coupling, or direct insertion to the $\mathrm{CB}$ surface, to the pre-modified $\mathrm{CB}$ 2 
is taking place (Scheme 4a-e). From the calculated surface loading by TGA of $1.0 \times 10^{14}$ molecules $/ \mathrm{cm}^{2}$ for $\mathrm{CB} \_2$ (Table 2), the expected weight loss of $\mathrm{CB} \_4 \mathrm{~b}$ can be estimated at $4.5 \times 10^{-4} \mathrm{~g}$ and $6.9 \times 10^{-4} \mathrm{~g}$ for single or dual insertion products, respectively. The measured weight loss of CB_4b by TGA was $8.7 \times 10^{-4} \mathrm{~g}$, suggesting that the dual insertion modification mechanism pre-dominates for the pre-functionalised CB_2.

Combustion Analysis (CHN). Further qualitative evidence by $\mathrm{CHN}$ confirmed the presence of nitrogen following surface modification (Table 1). Modified CB, CB_2, CB_4a and $\mathrm{CB} \_4 \mathrm{~b}$ all show the presence of nitrogen, which is consistent with the N-label functionality introduced in Route A. Furthermore, surface coverage estimates can be extracted from the CHN results (Table 2), assuming a monolayer surface coverage of the experimentally determined CB BET surface area $\left(72.5 \mathrm{~m}^{2} / \mathrm{g}\right)$. CHN estimates the surface loadings on $\mathrm{CB}$ to be in the range of $4.0 \times 10^{13}$ to $1.9 \times 10^{14}$ molecules $/ \mathrm{cm}^{2}$. These results are in good agreement with the TGA estimated surface coverage, and within the same order of magnitude. Additionally, it should be noted that nitrogen was also detected on CB_9b by $\mathrm{CHN}$ analysis, however this is expected due to contamination as it was not detected by XPS analysis, which has otherwise demonstrated a higher degree of sensitivity.

ATR-IR spectra. ATR-IR analysis of the two-step modified CB_4b (Figure 5) with the highest surface modification, further established the introduction of new functionality compared to pristine $\mathrm{CB}$. 


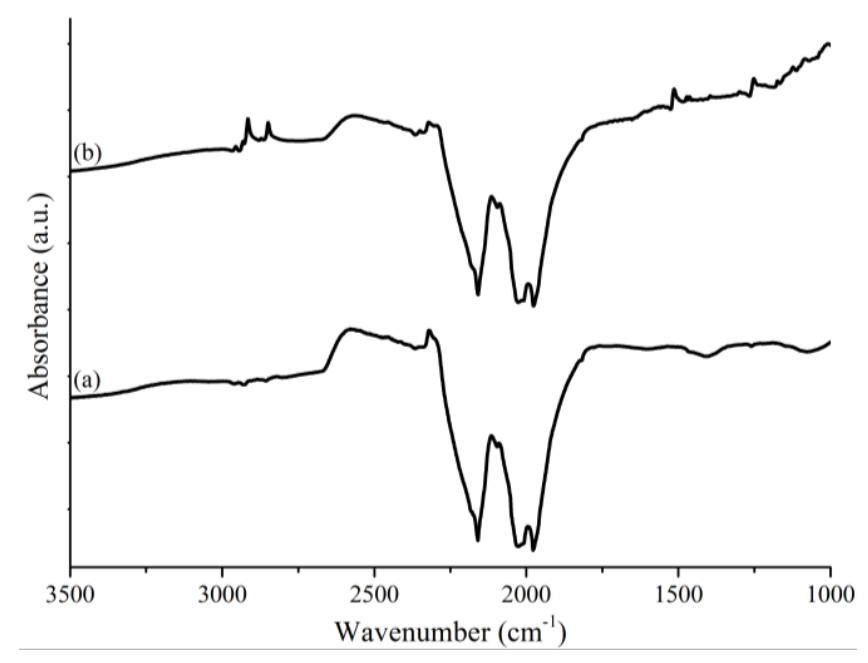

Figure 5. ATR-IR spectra of a) pristine CB and b) modified CB_4b.

Characteristic C-H symmetric and asymmetry bending bands were identified at $v 2916 \mathrm{~cm}^{-1}$ and $v 2849 \mathrm{~cm}^{-1}$ respectively, presumably from the introduction of the dodecyl hydrocarbon chain added in the diazonium coupling step. Further, a stretching band at $v 1514 \mathrm{~cm}^{-1}$ corresponded to aromatic $\mathrm{C}=\mathrm{C}$ and can be attributed to the benzene rings, and an aryl alkyl asymmetric stretch can be observed at $v 1251 \mathrm{~cm}^{-1}$ from the introduced C-O-C functionality in the diazonium coupling reaction, all of which are not observed for pristine $\mathrm{CB}$. Unfortunately, the trans azo $\mathrm{N}=\mathrm{N}$ stretching vibration in the $1400-1500 \mathrm{~cm}^{-1}$ region is typically rendered inactive on the IR spectrum ${ }^{37}$ and therefore, as expected, was not observed. The presence of functional groups for the other modified one-step and two-step CB samples could not be detected, presumably as result of being below the sensitivity limit for the ATRIR instrument. In addition, $\mathrm{CB}$ as a substrate is known to be difficult for ATR-IR spectroscopy, as it is an effective absorber and its high refractive index is also close to that of the diamond accessory. ${ }^{38}$

In summary, modified CB from Route A provided direct evidence of the introduction of nitrogen onto the $\mathrm{CB}$ nanoparticle surface and that surface functionalization by carbene and diazonium coupling reactions was successful. Next, Route B modified nanoparticles permits optimization of the functionalization method with a one-step approach for the introduction of 
steric stabilizing functional groups the CB surface. With this achieved, the potential of Route B modified CB samples for the improvement of polypropylene nanocomposites was investigated.

\section{Nanocomposite Preparation and Characterisation}

With modified CB nanoparticles in hand, polymer nanocomposites were prepared. Accordingly, PP was combined with pristine CB and covalently modified Route B, CB_9a and CB_9b, at varying filler additions, $10-30 \mathrm{wt} \%$ of PP. The volume conductivity of the resulting nanocomposites was then evaluated. Further analysis by dielectric analysis, TEM and STA was additionally carried out on selected nanocomposite samples.

Volume resistance - conductivity percolation curves. Improved electrical conductivity was a key aim of this study since it provides an indication on the nano-scale of the altered filler-filler and filler-polymer interfacial interactions following filler functionalization. The addition of conductive carbon-based fillers dispersed in insulating polymers, such as PP, induces electrical conductivity at a critical filler concentration, termed the percolation threshold. ${ }^{39}$ Before this point, upon addition of the nanofiller into the polymer matrix, the level of electrical conductivity rises gradually from the original polymer matrix. At the percolation threshold, the formation of continuous three-dimensional networks permits the passage of electrons through the nanocomposite, resulting in a significant increase in conductivity over a small range of nanofiller addition into the system. ${ }^{40,41}$ The formation of conductive networks can be seen in the TEM images of pristine CB in PP at 30 wt. \% in Figure 6. 

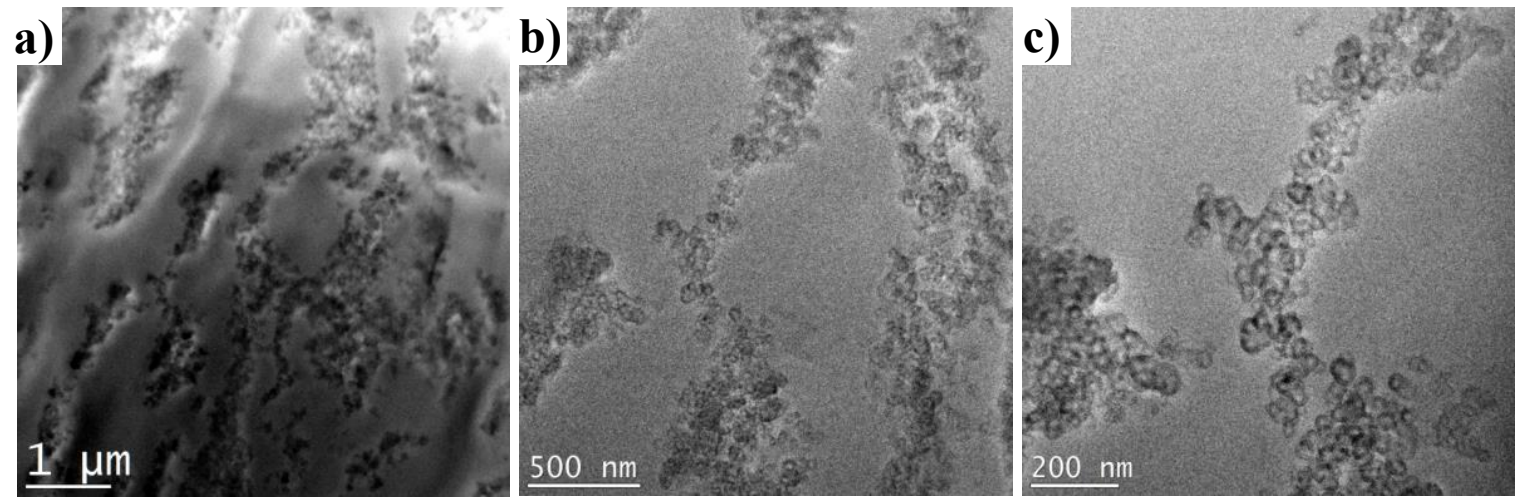

Figure 6. TEM images of pristine CB/PP at a) $1 \mu \mathrm{m}$ b) $500 \mathrm{~nm}$ and c) $200 \mathrm{~nm}$ resolution.

After the critical concentration has been reached, continued filler addition leads to a gradual increase in the conductivity measurements as the nanocomposite sample approaches the peak electrical conductivity of the filler.

The volume conductivities, as calculated from the measured sheet resistance of the pristine and modified $\mathrm{CB} / \mathrm{PP}$ nanocomposite samples, are presented in Figure 7 as a function of filler loading. Full details, including repeat experiments demonstrating the reproducibility of the measurements, are included in the Supporting Information.

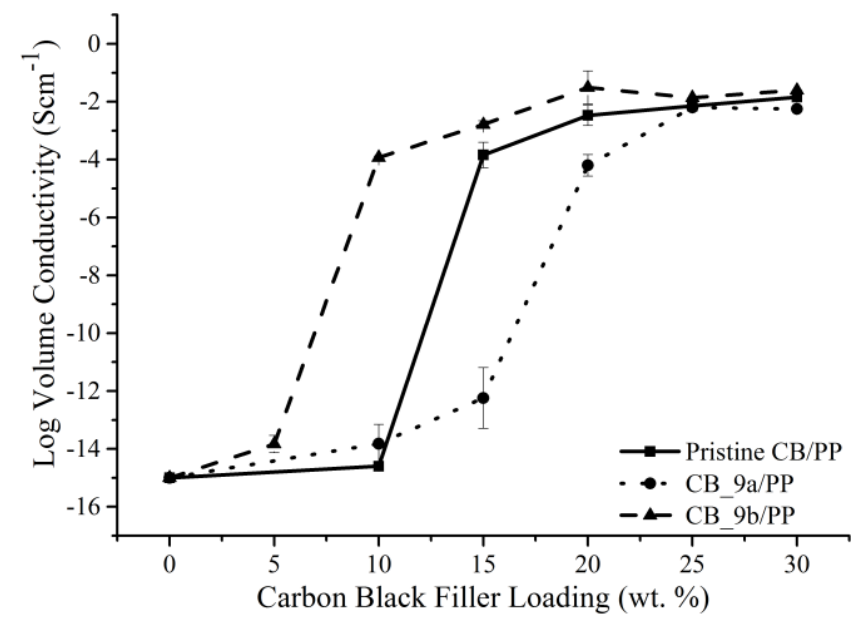

Figure 7. Logarithm of the volume electrical conductivity of pristine and modified $\mathrm{CB} / \mathrm{PP}$ nanocomposites as a function of $\mathrm{CB}$ nanofiller loading.

The electrical conductivity of the pristine $\mathrm{CB} / \mathrm{PP}$ nanocomposites increased significantly in the region from 10 to $20 \mathrm{wt}$ \% filler loading, with a percolation threshold starting to be 
reached around 15 wt. $\%$ with a conductivity in the order of $4.66 \times 10^{-4} \mathrm{Scm}^{-1}$. The high loading required to induce electrical conductivity is expected due to the low aspect ratio and low structure $\mathrm{CB}$ which was used, ${ }^{42}$ and this result is consistent with previous work on similar nanocomposite systems. ${ }^{43}$ The CB_9a/PP prepared nanocomposites, in which CB was covalently modified with a terminal hexyl chain, required an increased critical concentration of $\sim 20$ wt. $\%$ for the initial achievement of conductive three-dimensional networks in PP. This result indicates that the presence of even one polar ether group in the short side chain modifying group leads to an increased electrical percolation threshold, consistent with poor CB-PP matrix compatibilisation in the nanocomposite.

By contrast, $\mathrm{CB}$-9b/PP, in which the $\mathrm{CB}$ functionalization is terminated by a dodecyl chain, displayed high electrical conductivity at reduced filler loadings. Top conductivities of $2.51 \times 10^{-1} \mathrm{Scm}^{-1}$ were observed and the percolation threshold was beginning to be realized near 10 wt. \% loading with a conductivity of $1.19 \times 10^{-4} \mathrm{Scm}^{-1}$ (Figure 7). This result is likely due to favorable steric stabilization from the modification hindering CB agglomeration of aggregates, and assisted compatibilization between the functionalized CB and PP matrix. This reveals that the terminal dodecyl chain present on CB_9b, compared to hexyl terminated modification on CB_9a, is a viable nanoparticle modification for the production nanocomposite with improved properties. It is important to note here that the difference between the two covalently modified nanoparticles is unlikely to be as a result of the surface loading of the modifiers, as they were similar, with values of $7.1 \times 10^{13}$ and $2.4 \times 10^{13}$ molecules/cm² for CB_9a and CB_9b, respectively, as estimated by TGA.

Additionally, the volume conductivity was measured across both sides of the compressed molded nanocomposite plaques, permitting estimation of the error bars in Figure 7. The bidirectional analysis indicated an excellent level of sample homogeneity for the dodecyl 
modified CB_9b but a poorer level for the hexyl modified CB_9a, especially at a lower filler concentration, consistent with greater agglomeration in the system.

Dielectric analysis. Altered percolation thresholds of carbon-based polymer nanocomposites have been shown to exhibit promising dielectric properties, for example in electromagnetic interference (EMI) shielding applications. ${ }^{44}$ Further, testing nanocomposite samples close to the percolation threshold can provide information about the conductive mechanism of the nanocomposite samples. ${ }^{45}$ Figure 8 displays the real $\left(\varepsilon^{\prime}\right)$ and imaginary $(\varepsilon$ ') parts of the complex permittivity as a function of frequency of pure PP and pristine CB/PP, CB_9a/PP and CB_9b/PP nanocomposite samples at 20 wt. \% loading in the range 10 $\mathrm{MHz}-10 \mathrm{GHz}$.
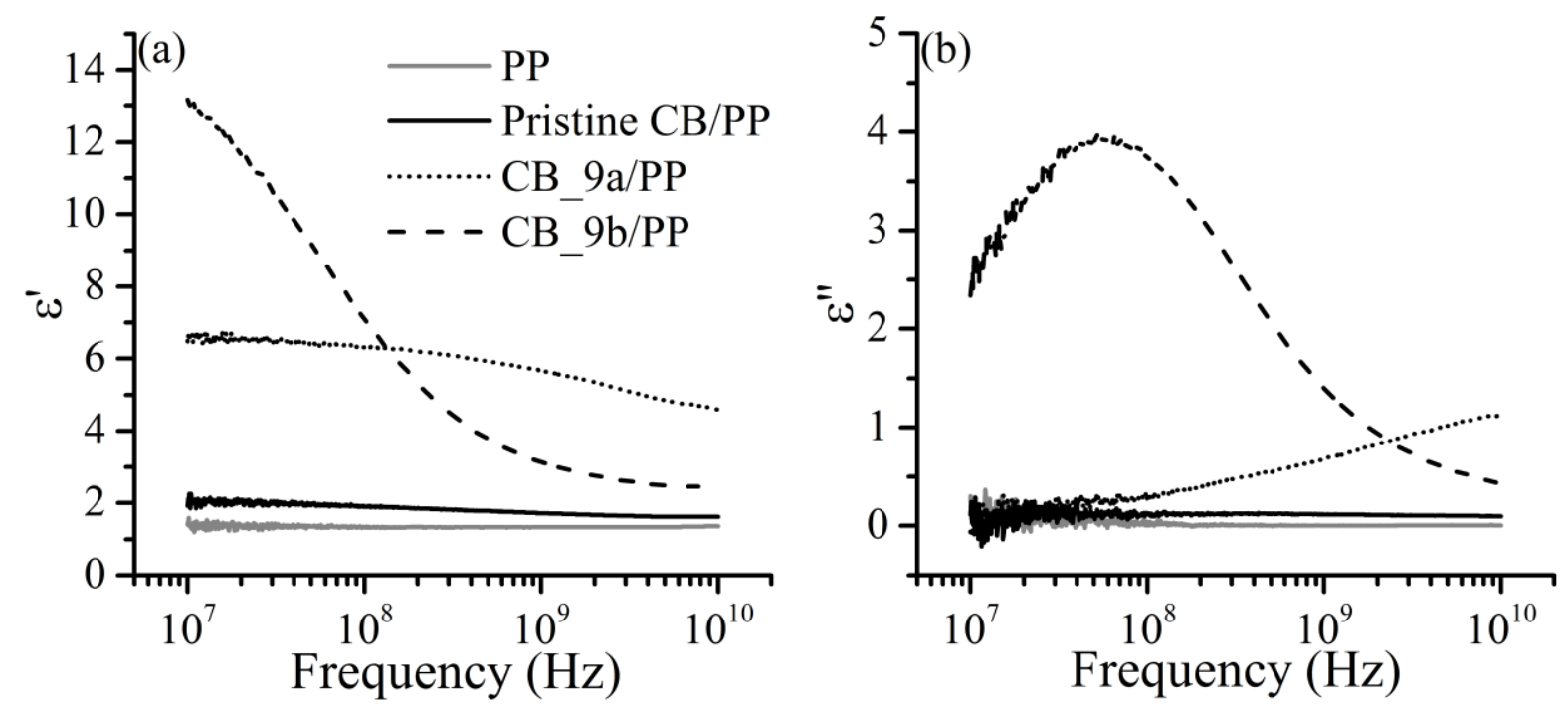

Figure 8. (a) Real part ( $\left.\varepsilon^{\prime}\right)$ and (b) the imaginary part ( $\varepsilon$ ') of the complex permittivity as a function of frequency, averaged over 50 repeat measurements at different points, of pure PP and pristine $\mathrm{CB} / \mathrm{PP}, \mathrm{CB} \_9 \mathrm{a} / \mathrm{PP}$ and $\mathrm{CB} \_9 \mathrm{~b} / \mathrm{PP}$ nanocomposite film samples $(15 \mu \mathrm{m})$, at 20 wt. \% loading in the range $10 \mathrm{MHz}-10 \mathrm{GHz}$.

For the real part $\left(\varepsilon^{\prime}\right)$ of the complex permittivity, which represents the capacity for electric energy storage, ${ }^{46}$ pure PP displays a frequency independent response at a value of 1.3 and pristine $\mathrm{CB} / \mathrm{PP}$ a low frequency dependent responses at 1.8. Modified CB nanocomposite 
samples, CB_9a/PP and CB_9b/PP, both display dielectric relaxation responses as the frequency is increased, indicating changed $\mathrm{CB}-\mathrm{CB}$ and $\mathrm{CB}-\mathrm{PP}$ interfacial interactions following the covalent modifications. In detail, CB_9a/PP displays an increased real permittivity of 6.5 at lower frequency measurements, reducing to 4.7 at the highest frequency recorded. In a similar trend, sample CB_9b/PP displays the greatest increase of real permittivity of 13.2 at lower frequency measurements, levelling to 2.4 at the highest frequency recorded. The imaginary part ( $\left.\varepsilon^{\prime \prime}\right)$ of the complex permittivity is related to the energy dissipation, accounting for conductive and relaxation effects of the nanocomposite sample. ${ }^{47}$ Similar to the real permittivity results, PP demonstrates a frequency independent response at a value of 0.03 and pristine $\mathrm{CB} / \mathrm{PP}$ a flat low frequency dependent response at 0.1 , both exhibiting non-conductive behavior at this frequency range. CB_9b/PP displayed a typical dielectric relaxation response with a maximal value $\sim 1 \times 10^{8} \mathrm{~Hz}$ while $\mathrm{CB}$ 9a/PP demonstrated a weaker dielectric response, which has shifted towards higher frequencies $\sim 1$ $\times 10^{10} \mathrm{~Hz}$

The observed frequency dependence, notably larger for CB_9b/PP compared to CB_9a/PP, is indicative of the conducting features of nanocomposites with increasing percolative correlation length as the percolation threshold is approached. ${ }^{48,}{ }^{49}$ At this measured loading, therefore, the electrical conductivity is influenced by inter-filler tunnelling. ${ }^{49}$ The observed frequency dependence is a result of the Maxwell-Wagner-Sillars effect, common to highly inhomogeneous systems such as nanocomposites comprising of conductive fillers embedded in an insulating polymer matrix. ${ }^{50}$ In the presence of an alternating current, interfacial polarisation can be induced at the interface between adjacent conductive CB clusters embedded in the PP matrix, resulting in a system of nanocapacitors, whereby the CB filler aggregates act as nanoelectrodes and the PP matrix as nanodielectrics. ${ }^{27,} 51$ The frequency dependent response of $\mathrm{CB}$ nanocomposites is largely directed by the $\mathrm{CB}$ loading and 
dispersion as well as the interfacial polarisation effects. ${ }^{52,53}$ Additionally, the surface chemistry of the filler, in this case the covalent modifications, can also have a direct effect on the electron tunnelling mechanism between adjacent $\mathrm{CB}$ clusters in the PP matrix, as demonstrated by these results as well as in other systems. ${ }^{54}$ In detail, as the sample is subjected to the alternating current, at lower frequencies interfacial polarisation follows the change in the electric field and maximal interfacial polarisation is obtained. As the frequency is increased, the alternating electrical field becomes too fast to induce polarisation effects, leading to dielectric relaxation and a reduced contribution to the real permittivity. ${ }^{42}$ In the imaginary part of the complex permittivity, there is a corresponding relaxation response, associated with induced oscillating interfacial polarisations. ${ }^{27}$ The greater frequency dependence upon the $\mathrm{CB}$-9b/PP sample indicates a more dispersed filler structure in this nanocomposite sample, with more nanocapacitors present concomitant with a greater polarisation density. ${ }^{28}$ On the other hand, the reduced frequency dependence of the CB_9a/PP sample is indicative of a more aggregated structure following the hexyl terminated CB surface functionalization.

As with the DC conductivity results, the variance of the repeat dielectric measurements ( $>50$ times) at different points on the nanocomposite films provides further evidence of the uniformity of the $\mathrm{CB}$ filler dispersion. The wide range of relaxation peaks observed for CB_9a/PP, included in the Supporting Information, further suggests that the dispersion is highly non-uniform over the length scale of the measurement (the probe has a $1.6 \mathrm{~mm}$ aperture). By contrast, the repeat relaxation peaks for $\mathrm{CB} \_9 \mathrm{~b} / \mathrm{PP}$ are more regular as a result of better dispersion and uniformity of the sample across measurement length scales.

It should be noted that microwave frequency dielectric measurements such as these reveal a great deal of useful information about connectivity, microstructure and electrodynamics in mixtures. ${ }^{55-57}$ As demonstrated in the results in Figure 8, major differences between 
percolative conduction in modified samples and in pristine samples are exposed; these are properties that DC measurements are unable to reveal. For $20 \mathrm{wt} \%$ loading at DC, percolation is well established and values of conductivity are similar for all samples, but at microwave frequencies it is clear that charge dynamics are very different for the modified and pristine samples. While the $\mathrm{DC}$ conductive pathways of the pristine $\mathrm{CB} / \mathrm{PP}$ composite are indeed well established at $20 \mathrm{wt}$ \% loading, the microwave measurements do not probe the macroscopic DC conductivity in this sample. There is a small frequency dependence of the pristine sample rising to an effective microwave permittivity value similar to that of PTFE at lower frequencies, unlike the frequency independent response of the PP sample, and this is entirely as expected. For the CB_9a/PP and CB_9b/PP samples, there is an increased frequency dependence because of the modified connectivity. However, this is not shown in the DC measurements, which - for any given loading value - provide limited information about conduction mechanisms. The large frequency dependence exhibited in the modified samples highlights the different conduction mechanisms associated with their modified connectivity.

Morphological characterisation. TEM micrographs and thin films $(15 \mu \mathrm{m})$ of the pristine and modified $\mathrm{CB} / \mathrm{PP}$ nanocomposites (Figure 9) provide a visual indication of the altered dispersion of the CB nanofiller in the region of the percolation threshold. 

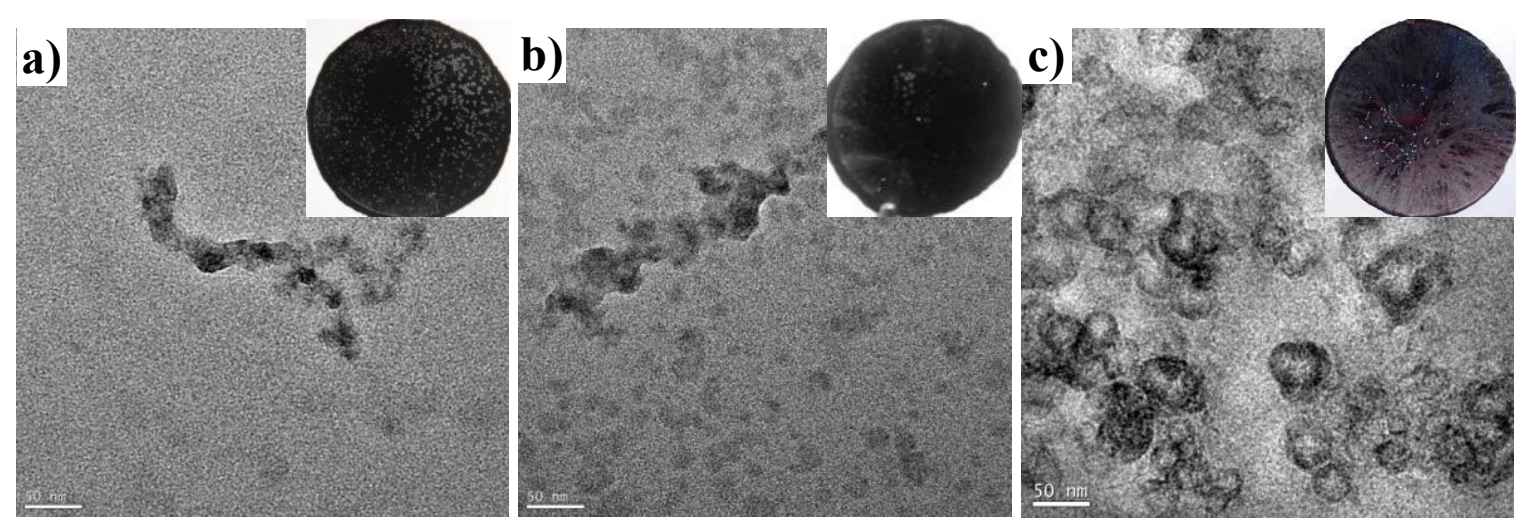

Figure

9. TEM micrographs for

a) pristine $\mathrm{CB} / \mathrm{PP}$

b) CB_9b/PP

c) CB_9a/PP

nanocomposites at a loading of $20 \mathrm{wt} \%$ at $50 \mathrm{~nm}$. Insert shows the nanocomposite films (15 $\mu \mathrm{m})$ used for the analysis.

Pristine CB displays a large isolated agglomerate in the polymer matrix and modified CB_9a also displays CB agglomerates and additionally visibly clustered PP. This further indicates the poor filler-polymer compatibilities and equally the unhindered attractive fillerfiller interactions following the hexyl-terminated nanoparticle functionalization. However, for modified CB_9b, good nanofiller dispersion in PP can be observed by the TEM image. A small agglomerate, or part of a conductive nanoparticle network is visible, and furthermore small dispersed CB aggregates are distributed across the TEM micrograph in accordance with the reported superior conductivity results. This result further indicates that covalent modified CB_9b has improved the compatibilisation between the filler and PP matrix.

Nanocomposite thermal properties. The melting and crystallization behavior of the pure PP and modified $\mathrm{CB} / \mathrm{PP}$ nanocomposites, extracted from the DSC runs in non-isothermal conditions, are reported in Table 3 . The determined degree of crystallinity $\left(X_{C}\right)$ was calculated as follows: $X_{C}=\frac{H_{m}}{(1-x) H_{0}} \times 100$

where $H_{m}$ is the sample melting enthalpy, as measured by DSC, $H_{0}$ is the melting enthalpy of $100 \%$ crystalline PP, which is reported to be $207.1 \mathrm{~J} / \mathrm{g}^{58,59}$, and $x$ is the weight fraction of CB present in the nanocomposite. ${ }^{60}$ 
Table 3. Thermal properties and degree of crystallinity of PP and prepared pristine and covalent modified CB_9a/PP and CB_9b/PP nanocomposites.

\begin{tabular}{|c|c|c|c|c|c|c|}
\hline Sample & $\begin{array}{c}\text { CB } \\
\text { Loading } \\
(\%)\end{array}$ & $\begin{array}{l}\mathrm{T}_{\text {oc }}{ }^{\mathrm{a}} \\
\left({ }^{\circ} \mathrm{C}\right)\end{array}$ & $\begin{array}{l}\mathrm{T}_{\mathrm{c}}^{\mathrm{b}} \\
\left({ }^{\mathbf{o}} \mathrm{C}\right)\end{array}$ & $\begin{array}{l}\mathbf{T}_{\mathbf{m}} \mathrm{c} \\
\left({ }^{\circ} \mathrm{C}\right)\end{array}$ & $\begin{array}{c}\Delta \mathbf{H}^{\mathbf{d}} \\
(\mathrm{J} / \mathrm{g})\end{array}$ & $\begin{array}{l}X_{C}{ }^{\mathrm{e}} \\
(\%)\end{array}$ \\
\hline Pure PP & 0 & 127.6 & 122.9 & 163.2 & 71.1 & 34 \\
\hline \multirow{5}{*}{$\begin{array}{l}\text { Pristine } \\
\mathrm{CB} / \mathrm{PP}\end{array}$} & 10 & 128.9 & 124.1 & 161.9 & 66.5 & 36 \\
\hline & 15 & 125.1 & 119.9 & 164.2 & 61.6 & 36 \\
\hline & 20 & 132.5 & 125.5 & 165.5 & 59.4 & 36 \\
\hline & 25 & 131.5 & 123.8 & 165.1 & 60.0 & 39 \\
\hline & 30 & 133.8 & 126.6 & 166.0 & 59.2 & 41 \\
\hline \multirow{5}{*}{ CB_9a/PP } & 10 & 121.3 & 115.8 & 162.5 & 57.7 & 31 \\
\hline & 15 & 125.2 & 117.4 & 166.2 & 57.8 & 33 \\
\hline & 20 & 126.3 & 120.7 & 163.7 & 57.3 & 35 \\
\hline & 25 & 127.7 & 121.2 & 165.8 & 56.8 & 37 \\
\hline & 30 & 129.1 & 121.7 & 167.4 & 54.8 & 38 \\
\hline \multirow{5}{*}{ CB_9b/PP } & 10 & 133.3 & 126.7 & 165.7 & 67.3 & 36 \\
\hline & 15 & 127.8 & 122.8 & 163.7 & 62.7 & 34 \\
\hline & 20 & 134.0 & 127.3 & 166.9 & 62.2 & 38 \\
\hline & 25 & 132.1 & 124.7 & 165.6 & 60.4 & 39 \\
\hline & 30 & 133.9 & 126.5 & 166.2 & 59.6 & 41 \\
\hline
\end{tabular}

${ }^{\mathrm{a}} \mathrm{T}_{\mathrm{oc}}$ is the crystallization onset temperature.

${ }^{\mathrm{b}} \mathrm{T}_{\mathrm{c}}$ is the crystallization peak temperature.

${ }^{\mathrm{c}} \mathrm{T}_{\mathrm{m}}$ Melting peak temperature (second melting cycle).

${ }^{\mathrm{d}} \Delta \mathrm{H}_{\mathrm{m}}$ Enthalpy of melting (second melting cycle).

${ }^{\mathrm{e}} X_{C}$ is the degree of crystallinity.

As a function of filler content, an increased nucleation efficiency of all the nanocomposite systems is indicated by the general increase in $T_{o c}, T_{c}$ and calculated degree of crystallinity. Although CB nanoparticles are known to collect in the amorphous regions of semi-crystalline polymers like PP, they can influence the crystalline structure. ${ }^{61}$ Accordingly, nanofillers can act as heterogeneous nucleation sites, initiating nucleation at higher temperatures closer to the melting temperature ${ }^{62}$ resulting in smaller, less uniform spherulites. ${ }^{63}$ As a result, this can increase the rate and degree of crystallinity when a filler is embedded in the polymer matrix of nanocomposites. ${ }^{48,64}$ Comparison of the samples at equal filler loading permits further consideration of the changes to the nucleation ability of the $\mathrm{CB}$ filler following surface modification. Once more, these changes can be attributed to changes in the filler-filler 
interfacial interactions as well as polymer-filler interfacial interactions, controlling the filler dispersion, and importantly provides an indication of the mechanical properties changes, such as the modulus and toughness, of the polymer nanocomposite. ${ }^{65}$ Figure 10 displays the cooling and Figure 11 the melting thermograms of the pristine and the modified $\mathrm{CB} / \mathrm{PP}$ nanocomposites at $20 \mathrm{wt} . \%$ loading.
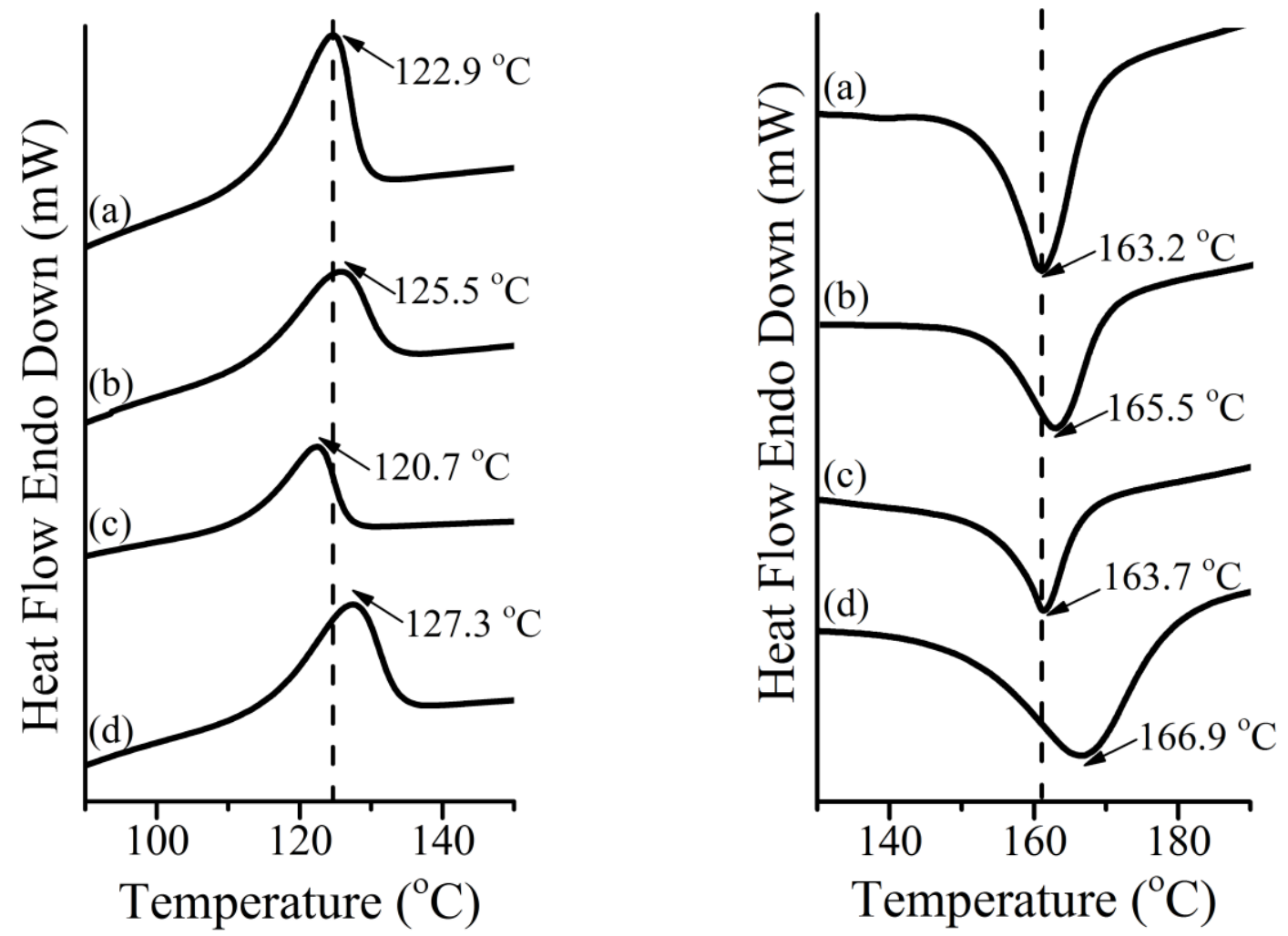

Figure 10. DSC cooling thermograms of a) Figure 11. DSC melting thermograms (second pure $\mathrm{PP}$ b) pristine $\mathrm{CB} / \mathrm{PP}$ c) $\mathrm{CB}$ _9a/PP and d) heating cycle) of a) pure $\mathrm{PP}$ b) pristine $\mathrm{CB} / \mathrm{PP}$ CB_9b/PP nanocomposites at 20 wt. \% filler c) CB_9a/PP and d) CB_9b/PP loading. nanocomposites at $20 \mathrm{wt} . \%$ filler loading.

It is evident from the $T_{c}$ values that a similar trend to the conductivity measurements can be observed. CB_9b/PP shows the largest $\mathrm{T}_{\mathrm{c}}$ increase compared to pure PP by $\sim 4{ }^{\circ} \mathrm{C}$, which can be compared to an increase of $\sim 2{ }^{\circ} \mathrm{C}$ for Pristine $\mathrm{CB} / \mathrm{PP}$. While only a small change, this result further supports improved filler dispersion following modification, which is directing an increased number of nucleation sites present at the same filler loading. Conversely, the $T_{c}$ 
of $\mathrm{CB}$-9a is lower than pristine $\mathrm{CB} / \mathrm{PP}$ by $\sim 5^{\circ} \mathrm{C}$, and is also lower than pure PP by $\sim 2{ }^{\circ} \mathrm{C}$. This further supports the evidence of the poor compatibility and poor dispersion of this hexylterminated CB modification with PP. Figure 11 also reveals a similar trend for the $\mathrm{T}_{\mathrm{m}}$ values, with the most dispersed system, CB_9b/PP, showing the highest melting temperature. Raised $\mathrm{T}_{\mathrm{m}}$ values following filler addition is indicative of decreased lamellar thickness in a more ordered PP matrix and is observed due to the increased nucleation ability of the most dispersed CB_9b/PP system. ${ }^{66}$

With regards to the degree of crystallinity results, it can be observed that at low filler additions of 10 wt. $\%$ and 15 wt. \%, CB_9a/PP nanocomposite displayed low $X_{C}$ values of 31 $\%$ and $33 \%$, respectively. It is worth noting that this is lower than the $X_{C}$ of pure PP, $34 \%$, and this result can be attributed to the presence of large $\mathrm{CB}$ agglomerates which may be restricting PP chain movement as well as hindering effective polymer chain packing. ${ }^{65}$ Finally, above 20 wt. \% filler loading of CB_9a/PP, the $X_{C}$ of the nanocomposite surpasses pure PP, with an eventual $X_{C}$ of $38 \%$ at maximum loading. Pristine CB/PP and CB_9b/PP nanocomposites both immediately display increased $X_{C}$ compared to pure PP, with the CB_9b/PP nanocomposite displaying a notably higher degree of crystallinity at $20 \mathrm{wt}$ \% loading, a result again indicative of the nucleation capability of this modified CB filler. Finally, it is evident that the reported degree of crystallinity (Table 3) follows a similar trend to the nanocomposite conductivity measurements (Figure 7). Previous studies have also found corresponding results between the nucleation effect of filler nanoparticles and the conductivity measurements above the percolation threshold. ${ }^{67}$ 


\section{CONCLUSIONS}

In summary, the use of two covalent approaches for the tailored functionalization of $\mathrm{CB}$ nanoparticles for polymer nanocomposite applications has been clearly demonstrated. Route A used a two-step approach, involving carbene insertion followed by diazonium coupling reactions, to introduce an N-label terminated by hexyl and dodecyl hydrocarbon chains to the CB surface. Route B applied the same carbene functionalization technology in an optimized one-step approach, in which the CB was directly modified with a tailored hexyl and dodecyl terminated diaryl complex. Direct evidence of the altered surface chemistry of $\mathrm{CB}$, including the introduction of nitrogen functionality, was found by TGA, CHN, XPS, ATR-IR analysis and grafting densities estimated to be in the order of $10^{13}$ and $10^{14}$ molecules $/ \mathrm{cm}^{2}$ for the modified samples.

The application of modified CB_9a-b for use in PP nanocomposites was investigated. The macroscopic property changes in the resulting $\mathrm{CB} / \mathrm{PP}$ nanocomposites further indicate the changed $\mathrm{CB}$ surface chemistry and altered $\mathrm{CB}-\mathrm{CB}$ and $\mathrm{CB}-\mathrm{PP}$ interfacial interactions following the carbene functionalization approach. Interestingly, the hexyl-terminated covalent Route $\mathrm{B}$ modification of $\mathrm{CB}_{-} 9 \mathrm{a}$ resulted in an increased percolation threshold compared to pristine $\mathrm{CB} / \mathrm{PP}$ nanocomposites, indicating increased $\mathrm{CB}$ agglomeration in the nanocomposite system. TEM micrographs, dielectric analysis and STA thermal properties further corroborated this result. We attribute this effect might be a result of the modification reducing the CB-PP compatibility, or equally enhancement of the $\mathrm{CB}$ filler-filler interactions, or a combination of the two effects, leading to aggregated, poorly dispersed and distributed $\mathrm{CB}$ in the PP matrix. On the other hand, TEM micrographs of dodecyl terminated Route B modified CB_9b visibly demonstrated improved dispersion of $\mathrm{CB}$ aggregates and reduced CB agglomerate formation. Correlation with STA data illustrated increased crystallization temperatures following $\mathrm{CB}$ modification, and indicated an increased number of nucleation 
sites owing to separated and dispersed $\mathrm{CB}$ aggregates present in the nanocomposite. Correspondingly, enhanced dielectric and electrical properties were observed. The electrical percolation threshold of the covalent modified CB_9b/PP was reduced to $\sim 10$ wt. \% filler addition, almost half the required filler loading to achieve conductivity for pristine $\mathrm{CB} / \mathrm{PP}$ nanocomposites. Finally, this versatile carbene $\mathrm{CB}$ modification strategy highlights the potential of tailored nanoparticle functionalization in the pursuit of superior, multifunctional nanocomposites. 


\section{ASSOCIATED CONTENT}

Detailed synthesis procedures of the organic compounds including compound spectra, XPS analysis of the $\mathrm{C} 1 \mathrm{~s}$ and $\mathrm{O}$ 1s regions of pristine and modified $\mathrm{CB}$, raw XPS, ATR-IR, BET, CHN and TGA data of pristine and modified CB, TGA and CHN surface loading calculations of modified $\mathrm{CB}$, and raw $\mathrm{CB} / \mathrm{PP}$ nanocomposite conductivity, dielectric and STA data are included in the Supporting Information. This material is available free of charge via the Internet at http://pubs.acs.org.

\section{AUTHOR INFORMATION}

\section{Corresponding Author}

*Email: Mark.moloney@chem.ox.ac.uk

\section{ACKNOWLEDGMENTS}

This work was supported by IRPC Public Company Limited. We gratefully acknowledge Robert Jacobs and Ashley Shepherd from the Oxford Surface Analysis Facility for their assistance with the ATR-IR and XPS surface analysis and Jerome Cuenca from Cardiff University for insightful discussions regarding the dielectric analysis. 


\section{REFERENCES}

1. Zhang, W.; Dehghani-Sanij, A. A.; Blackburn, R. S., Carbon based conductive polymer composites. Journal of Materials Science 2007, 42, (10), 3408-3418.

2. Wen, X.; Wang, Y.; Gong, J.; Liu, J.; Tian, N.; Wang, Y.; Jiang, Z.; Qiu, J.; Tang, T., Thermal and flammability properties of polypropylene/carbon black nanocomposites. Polymer Degradation and Stability 2012, 97, (5), 793-801.

3. Tjong, S. C., Structural and mechanical properties of polymer nanocomposites. Materials Science and Engineering: R: Reports 2006, 53, (3-4), 73-197.

4. Ritzhaupt-Kleissl, E.; Boehm, J.; Hausselt, J.; Hanemann, T., Thermoplastic polymer nanocomposites for applications in optical devices. Materials Science and Engineering: $C$ 2006, 26, (5-7), 1067-1071.

5. Díez-Pascual, A. M.; Díez-Vicente, A. L., Development of Nanocomposites Reinforced with Carboxylated Poly(ether ether ketone) Grafted to Zinc Oxide with Superior Antibacterial Properties. ACS Applied Materials \& Interfaces 2014, 6, (5), 3729-3741.

6. Huang, S.; Wang, M.; Liu, T.; Zhang, W.-D.; Tjiu, W. C.; He, C.; Lu, X., Morphology, thermal, and rheological behavior of nylon 11/multi-walled carbon nanotube nanocomposites prepared by melt compounding. Polymer Engineering \& Science 2009, 49, (6), 1063-1068.

7. Gulrez, S. K. H.; Ali Mohsin, M. E.; Shaikh, H.; Anis, A.; Pulose, A. M.; Yadav, M. K.; Qua, E. H. P.; Al-Zahrani, S. M., A review on electrically conductive polypropylene and polyethylene. Polymer Composites 35, (5), 900-914.

8. Tchoudakov, R.; Breuer, O.; Narkis, M.; Siegmann, A., Conductive polymer blends with low carbon black loading: Polypropylene/polyamide. Polymer Engineering and Science 1996, 36, (10), 1336-1346.

9. Medalia, A. I.; Heckman, F. A., Morphology of aggregates-II. Size and shape factors of carbon black aggregates from electron microscopy. Carbon 1969, 7, (5), 567-582.

10. Kost, J.; Narkis, M.; Foux, A., Resistivity Behavior of Carbon-Black-Filled SiliconeRubber in Cyclic Loading Experiments. Journal of Applied Polymer Science 1984, 29, (12), 3937-3946.

11. Narkis, M.; Lidor, G.; Vaxman, A.; Zuri, L., New injection moldable ESD compounds based on very low carbon black loadings. Electrical Overstress/Electrostatic Discharge Symposium Proceedings - 1998 1998, 1-9.

12. Moniruzzaman, M.; Winey, K. I., Polymer nanocomposites containing carbon nanotubes. Macromolecules 2006, 39, (16), 5194-5205.

13. Luksirikul, P.; Ballesteros, B.; Tobias, G.; Moloney, M. G.; Green, M. L. H., Sidewall functionalisation of carbon nanotubes by addition of diarylcarbene derivatives. Journal of Materials Chemistry 2011, 21, (47), 19080-19085.

14. Luksirikul, P.; Ballesteros, B.; Tobias, G.; Moloney, M. G.; Green, M. L. H., pHtriggered release of materials from single-walled carbon nanotubes using dimethylaminofunctionalized fullerenes as removable "corks". Carbon 2010, 48, (7), 1912-1917.

15. Wang, H.; Griffiths, J. P.; Egdell, R. G.; Moloney, M. G.; Foord, J. S., Chemical functionalization of diamond surfaces by reaction with diaryl carbenes. Langmuir 2008, 24, (3), 862-868.

16. Leonard, D.; Moloney, M. G.; Thompson, C., Chemical modification of materials by reaction with diaryl diazomethanes. Tetrahedron Letters 2009, 50, (26), 3499-3502.

17. Choong, C.; Foord, J. S.; Griffiths, J. P.; Parker, E. M.; Luo, B. W.; Bora, M.; Moloney, M. G., Post-polymerisation modification of surface chemical functionality and its effect on protein binding. New Journal of Chemistry 2012, 36, (5), 1187-1200. 
18. Bagwell, C. L.; Leonard, D. M. L.; Griffiths, J.-P.; Moloney, M. G.; Stratton, N. J.; Travers, D. P., Post-Polymerization Modification of Materials using Diaryldiazomethanes: Changes to Surface Macroscopic Properties. Macromolecular Reaction Engineering 2014, 8, (2), 170-180.

19. Awenat, K. M.; Davis, P. J.; Moloney, M. G.; Ebenezer, W., A chemical method for the convenient surface functionalisation of polymers. Chemical Communications 2005, (8), 990-992.

20. Griffiths, J. P.; Maliha, B.; Moloney, M. G.; Thompson, A. L.; Hussain, I., Surface Functional Polymers by Post-Polymerization Modification using Diarylcarbenes: Introduction, Release and Regeneration of Hydrogen Peroxide and Bactericidal Activity. Langmuir 2010, 26, (17), 14142-14153.

21. Choong, C.; Griffiths, J. P.; Moloney, M. G.; Triffitt, J.; Swallow, D., Direct introduction of phosphonate by the surface modification of polymers enhances biocompatibility. Reactive \& Functional Polymers 2009, 69, (2), 77-85.

22. Griffiths, J.-P.; Leonard, D. M. 1.; Moloney, M. G.; Stratton, N. J., Control of wetting behavior using post-polymerization modifications of surface chemical functionality. Journal of Molecular and Engineering Materials 2013, 01, (01), 1250002.

23. Toupin, M.; Belanger, D., Thermal stability study of aryl modified carbon black by in situ generated diazonium salt. Journal of Physical Chemistry C 2007, 111, (14), 5394-5401.

24. Su, F.; Poh, C. K.; Chen, J. S.; Xu, G.; Wang, D.; Li, Q.; Lin, J.; Lou, X. W., Nitrogen-containing microporous carbon nanospheres with improved capacitive properties. Energy \& Environmental Science 2011, 4, (3), 717-724.

25. Gulrez, S. K. H.; Ali Mohsin, M. E.; Shaikh, H.; Anis, A.; Pulose, A. M.; Yadav, M. K.; Qua, E. H. P.; Al-Zahrani, S. M., A review on electrically conductive polypropylene and polyethylene. Polymer Composites 2014, 35, (5), 900-914.

26. Zhang, K.; Park, B.-J.; Fang, F.-F.; Choi, H. J., Sonochemical preparation of polymer nanocomposites. Molecules 2009, 14, (6), 2095-2110.

27. Arjmand, M.; Sundararaj, U., Broadband dielectric properties of multiwalled carbon nanotube/polystyrene composites. Polymer Engineering \& Science 2015, 55, (1), 173-179.

28. Ma, P.-C.; Liu, M.-Y.; Zhang, H.; Wang, S.-Q.; Wang, R.; Wang, K.; Wong, Y.-K.; Tang, B.-Z.; Hong, S.-H.; Paik, K.-W.; Kim, J.-K., Enhanced Electrical Conductivity of Nanocomposites Containing Hybrid Fillers of Carbon Nanotubes and Carbon Black. ACS Applied Materials \& Interfaces 2009, 1, (5), 1090-1096.

29. Panchompoo, J.; Aldous, L.; Compton, R. G., Size-effects in the chemical modification of carbon black nanoparticles with 4-nitroaniline. New Journal of Chemistry 2010, 34, (11), 2643-2653.

30. Toupin, M.; Bélanger, D., Spontaneous Functionalization of Carbon Black by Reaction with 4-Nitrophenyldiazonium Cations. Langmuir 2008, 24, (5), 1910-1917.

31. Belmont, J. A.; Amici, R. M.; Galloway, C. P., Carbon black reacted with diazonium salts and products. In Google Patents: 1996.

32. Shin, S. H.; Cizmeciyan, D.; Keating, A. E.; Khan, S. I.; Garcia-Garibay, M. A., Control of Carbene Reactivity by Crystals. A Highly Selective 1,2-H Shift in the Solid-toSolid Reaction of 1-(4'-Biphenylyl)-2-phenyldiazopropane to (Z)-1-(4'-Biphenylyl)-2phenylpropene. Journal of the American Chemical Society 1997, 119, (8), 1859-1868.

33. Zawadiak, J.; Hefczyc, B.; Janeczek, H.; Kowalczuk, M., Synthesis and thermal properties of azo-peroxyesters. Monatshefte für Chemie - Chemical Monthly 2009, 140, (3), 303-308.

34. Toupin, M.; Belanger, D., Spontaneous functionalization of carbon black by reaction with 4-nitrophenyldiazonium cations. Langmuir 2008, 24, (5), 1910-1917. 
35. Dyke, C. A.; Stewart, M. P.; Tour, J. M., Separation of Single-Walled Carbon Nanotubes on Silica Gel. Materials Morphology and Raman Excitation Wavelength Affect Data Interpretation. Journal of the American Chemical Society 2005, 127, (12), 4497-4509.

36. Borah, D.; Satokawa, S.; Kato, S.; Kojima, T., Characterization of chemically modified carbon black for sorption application. Applied Surface Science 2008, 254, (10), 3049-3056.

37. Silverstein, R. M.; Webster, F. X.; Kiemle, D. J., Spectrometric Identification of Organic Compounds. 7th Edition ed.; John Wiley \& Sons 2005.

38. Wilhelm, P., Applications of FT-IR microscopy with materials analyses. Micron 1996, 27, (5), 341-344.

39. Stauffer, D., Introduction of Percolation Theory. 1985, Talyor and Francis: London, UK.

40. Potschke, P.; Fornes, T. D.; Paul, D. R., Rheological behavior of multiwalled carbon nanotube/polycarbonate composites. Polymer 2002, 43, (11), 3247-3255.

41. Potts, J. R.; Dreyer, D. R.; Bielawski, C. W.; Ruoff, R. S., Graphene-based polymer nanocomposites. Polymer 2011, 52, (1), 5-25.

42. Sui, G.; Jana, S.; Zhong, W. H.; Fuqua, M. A.; Ulven, C. A., Dielectric properties and conductivity of carbon nanofiber/semi-crystalline polymer composites. Acta Materialia 2008, $56,(10), 2381-2388$.

43. Li, Y.; Wang, S.; Zhang, Y.; Zhang, Y., Electrical properties and morphology of polypropylene/epoxy/glass fiber composites filled with carbon black. Journal of Applied Polymer Science 2005, 98, (3), 1142-1149.

44. Yousefi, N.; Sun, X. Y.; Lin, X. Y.; Shen, X.; Jia, J. J.; Zhang, B.; Tang, B. Z.; Chan, M. S.; Kim, J. K., Highly Aligned Graphene/Polymer Nanocomposites with Excellent Dielectric Properties for High-Performance Electromagnetic Interference Shielding. Advanced Materials 2014, 26, (31), 5480-5487.

45. Li, Y. C.; Li, R. K. Y.; Tjong, S. C., Frequency and Temperature Dependences of Dielectric Dispersion and Electrical Properties of Polyvinylidene Fluoride/Expanded Graphite Composites. Journal of Nanomaterials 2010, 2010, 10.

46. Dang, Z. M.; Shehzad, K.; Zha, J. W.; Mujahid, A.; Hussain, T.; Nie, J.; Shi, C. Y., Complementary percolation characteristics of carbon fillers based electrically percolative thermoplastic elastomer composites. Composites Science and Technology 2011, 72, (1), 2835 .

47. Qing, Y. C.; Zhou, W. C.; Jia, S.; Luo, F.; Zhu, D. M., Electromagnetic and microwave absorption properties of carbonyl iron and carbon fiber filled epoxy/silicone resin coatings. Applied Physics a-Materials Science \& Processing 2010, 100, (4), 1177-1181.

48. Logakis, E.; Pollatos, E.; Pandis, C.; Peoglos, V.; Zuburtikudis, I.; Delides, C. G.; Vatalis, A.; Gjoka, M.; Syskakis, E.; Viras, K.; Pissis, P., Structure-property relationships in isotactic polypropylene/multi-walled carbon nanotubes nanocomposites. Composites Science and Technology 2010, 70, (2), 328-335.

49. Yu, C. R.; Wu, D. M.; Liu, Y.; Qiao, H.; Yu, Z. Z.; Dasari, A.; Du, X. S.; Mai, Y. W., Electrical and dielectric properties of polypropylene nanocomposites based on carbon nanotubes and barium titanate nanoparticles. Composites Science and Technology 2011, 71, (15), 1706-1712.

50. Yacubowicz, J.; Narkis, M., Dielectric Behavior of Carbon-Black Filled Polymer Composites. Polymer Engineering and Science 1986, 26, (22), 1568-1573.

51. Dang, Z. M.; Yao, S. H.; Yuan, J. K.; Bai, J. B., Tailored Dielectric Properties based on Microstructure Change in BaTiO3-Carbon Nanotube/Polyvinylidene Fluoride ThreePhase Nanocomposites. Journal of Physical Chemistry C 2010, 114, (31), 13204-13209. 
52. Jianwen, X.; Wong, M.; Wong, C. P. In Super high dielectric constant carbon blackfilled polymer composites as integral capacitor dielectrics, Electronic Components and Technology Conference, 2004. Proceedings. 54th, 1-4 June 2004, 2004; 2004; pp 536-541 Vol.1.

53. Song, Y.; Noh, T. W.; Lee, S. I.; Gaines, J. R., Experimental-Study of the 3Dimensional Ac Conductivity and Dielectric-Constant of a Conductor-Insulator Composite near the Percolation-Threshold. Physical Review B 1986, 33, (2), 904-908.

54. Xu, H. P.; Dang, Z. M.; Jiang, M. J.; Yao, S. H.; Bai, J., Enhanced dielectric properties and positive temperature coefficient effect in the binary polymer composites with surface modified carbon black. Journal of Materials Chemistry 2008, 18, (2), 229-234.

55. Youngs, I. J.; Bowler, N.; Lymer, K. P.; Hussain, S., Dielectric relaxation in metalcoated particles: the dramatic role of nano-scale coatings. Journal of Physics D: Applied Physics 2005, 38, (2), 188.

56. Brosseau, C.; Bourbigot, C.; Beroual, A.; Queffelec, P.; Mest, Y. L.; Loaec, J. In Dielectric and microstructure properties of polymer carbon-black composites, Conference Record of the 1996 IEEE International Symposium on Electrical Insulation, 16-19 Jun 1996, 1996; 1996; pp 850-853 vol.2.

57. Hotta, M.; Hayashi, M.; Lanagan, M. T.; Agrawal, D. K.; Nagata, K., Complex Permittivity of Graphite, Carbon Black and Coal Powders in the Ranges of X-band Frequencies (8.2 to $12.4 \mathrm{GHz}$ ) and between 1 and $10 \mathrm{GHz}$. ISIJ International 2011, 51, (11), 1766-1772.

58. Wunderlich, B., Thermal Analysis 1990, Academic Press, New York, NY, USA.

59. Li, Y.; Sundararaj, U., Comparative study on electrical properties of copper nanowire/polypropylene and carbon nanotube/polypropylene composites. AIChE Journal 2015, 61, (1), 296-303.

60. Zhang, H.; Zhang, Z., Impact behaviour of polypropylene filled with multi-walled carbon nanotubes. European Polymer Journal 2007, 43, (8), 3197-3207.

61. Mucha, M.; Marszałek, J.; Fidrych, A., Crystallization of isotactic polypropylene containing carbon black as a filler. Polymer 2000, 41, (11), 4137-4142.

62. Bikiaris, D., Microstructure and Properties of Polypropylene/Carbon Nanotube Nanocomposites. Materials 2010, 3, (4), 2884-2946.

63. Vassiliou, A.; Bikiaris, D.; Chrissafis, K.; Paraskevopoulos, K. M.; Stavrev, S. Y.; Docoslis, A., Nanocomposites of isotactic polypropylene with carbon nanoparticles exhibiting enhanced stiffness, thermal stability and gas barrier properties. Composites Science and Technology 2008, 68, (3-4), 933-943.

64. Assouline, E.; Lustiger, A.; Barber, A. H.; Cooper, C. A.; Klein, E.; Wachtel, E.; Wagner, H. D., Nucleation ability of multiwall carbon nanotubes in polypropylene composites. Journal of Polymer Science Part B: Polymer Physics 2003, 41, (5), 520-527.

65. Manchado, M. A. L.; Valentini, L.; Biagiotti, J.; Kenny, J. M., Thermal and mechanical properties of single-walled carbon nanotubes-polypropylene composites prepared by melt processing. Carbon 2005, 43, (7), 1499-1505.

66. Chrissafis, K.; Paraskevopoulos, K. M.; Stavrev, S. Y.; Docoslis, A.; Vassiliou, A.; Bikiaris, D. N., Characterization and thermal degradation mechanism of isotactic polypropylene/carbon black nanocomposites. Thermochimica Acta 2007, 465, (1-2), 6-17.

67. Li, Y. F.; Zhu, J. H.; Wei, S. Y.; Ryu, J. E.; Wang, Q.; Sun, L. Y.; Guo, Z. H., Poly(propylene) Nanocomposites Containing Various Carbon Nanostructures. Macromolecular Chemistry and Physics 2011, 212, (22), 2429-2438. 


\section{TOC Graphic}

Modified CB/PP _ Carbene-Based

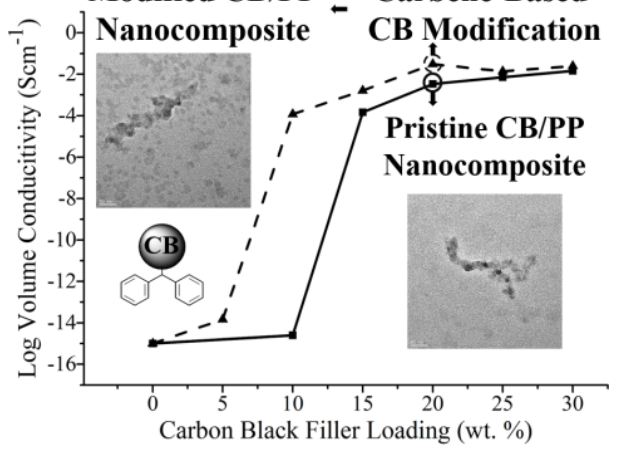

